\title{
Article \\ Electromagnetic Torque Ripple in Multiple Three-Phase Brushless DC Motors for Electric Vehicles
}

\author{
Ihor Shchur ${ }^{1}$ (D) and Daniel Jancarczyk ${ }^{2, *(D)}$ \\ 1 Department of Electric Mechatronics and Computer-Controlled Electromechanical Systems, \\ Lviv Polytechnic National University, 79013 Lviv, Ukraine; ihor.z.shchur@lpnu.ua \\ 2 Department of Computer Science and Automatics, University of Bielsko-Biala, 43-309 Bielsko-Biala, Poland \\ * Correspondence: djancarczyk@ath.bielsko.pl
}

check for updates

Citation: Shchur, I.; Jancarczyk, D. Electromagnetic Torque Ripple in Multiple Three-Phase Brushless DC Motors for Electric Vehicles. Electronics 2021, 10, 3097. https:/ / doi.org/10.3390/electronics10243097

Academic Editor: Lucia Frosini

Received: 20 November 2021 Accepted: 10 December 2021 Published: 13 December 2021

Publisher's Note: MDPI stays neutral with regard to jurisdictional claims in published maps and institutional affiliations.

Copyright: (c) 2021 by the authors. Licensee MDPI, Basel, Switzerland. This article is an open access article distributed under the terms and conditions of the Creative Commons Attribution (CC BY) license (https:// creativecommons.org/licenses/by/ $4.0 /)$.

\begin{abstract}
This paper investigated an electromagnetic torque ripple level of BLDC drives with multiple three-phase (TP) permanent magnet (PM) motors for electric vehicles. For this purpose, mathematical models of PM machines of different armature winding sets-single (STP), dual (DTP), triple (TTP), and quadruple (QTP) ones of asymmetrical configuration and optimal angular displacement between winding sets were developed and corresponding computer models in the Matlab/Simulink environment were created. In conducted simulation, the influence of various factors on the electromagnetic torque ripple of the multiple-TP BLDC drives was investigated-degree of modularity, magnetic coupling between armature winding sets, and drive operation in open and closed-loop control systems. Studies have shown an increase of the electromagnetic torque ripple generated by one module in the multiple TP BLDC drives with magnetically coupled winding sets, due to additional current pulsations caused by magnetic interactions between the machine modules. However, the total electromagnetic torque ripples are much lower than in similar drives with magnetically insulated winding sets. Compared with the STP BLDC drive, the multiple TP BLDC drives with the same output parameters showed a reduction of the electromagnetic torque ripple by $27.6 \%$ for the DTP, $32.3 \%$ for the TTP, and $34.0 \%$ for the QTP BLDC drive.
\end{abstract}

Keywords: electric vehicle (EV); multiple three-phase permanent magnet (PM) motor; BLDC drive; electromagnetic torque ripple; fractional slot concentrated winding; magnetic coupling; self and mutual inductances; Matlab/Simulink model

\section{Introduction}

In recent years, the world has seen rapid development of electric vehicle (EV) engineering. Unlike cars, a number of new qualities characterize EVs, such as much higher efficiency, simplified design, especially of the mechanical transmission, increased automation of all subsystems, improved handling, stability and safety, increased reliability, and reduced need for maintenance of all subsystems [1]. All these positive qualities of EVs can be enhanced through new approaches to configuring their main subsystems and applying appropriate control principles. One of the most productive of these approaches, in our view, is a modular approach in the design of powertrain subsystems-on-board power systems, electrical machines, and power semiconductor converters, which combine individual modules and control power flows [2-5].

Multiphase and modular electric AC drives have become the subject of considerable interest over the past two decades [6-8]. Modular asynchronous and then synchronous electric machines were originally designed exclusively for use in high-power facilities with medium voltage levels that allowed them to be effectively controlled by means of modern power electronics. Among such applications are generators of powerful wind turbines [9] and electric drives of powerful vehicles [10-12]. Known advantages of modular drives in comparison with traditional three-phase ones include higher efficiency, reduced power per module and phase, lower supply DC link voltage of the modules, reduced 
harmonic content of the DC current, and reduction of the torque ripple. In addition, modular drives have a much higher reliability and safety due to fault tolerance, their production is cheaper, and maintenance and repair are easier [2,13]. For EVs, these benefits are especially important. As the EV drive constantly works in the conditions of variable speed and loading, the modular electric drive gives a chance for the work of various number of modules with the maximum approximation of their loading to nominal values. In this case, the electric machine and the power inverter are characterized by the maximum values of their efficiency, which minimizes energy losses and increases the EV range on a single charge [14]. Compared to traditional drives for EVs, modular motor drives are inherently fault tolerant because failure in one of the modules does not lead to complete loss of control of the vehicle.

Modular electric machines with multiple windings have already been applied in the cases where a fault tolerant operation of EVs should be insured, e.g., for electric power steering [15], electric aircraft [16], or unmanned EVs [17]. The positive qualities of such drives have led to the following solutions for the use of modular electric machines: in particular modular three-phase (TP), in EVs drives with low and medium power levels and low voltages [18]. However, it is associated with significant hardware and software complexity of such drive systems. To increase the popularity of modular drives for different EVs, it is necessary to provide a good trade-off between the added complexity and potential benefits.

To significantly simplify the modular multiple TP drive, we propose to use a modular brushless DC motor (BLDCM) with permanent magnets (PM) [19]. Known advantages of this drive are the use of a simpler design of an electric machine with PMs placed on the rotor surface, cheap point sensors of an angular position of the rotor, discrete low frequency switching of armature windings, and a simple control system [20]. Low voltage of the BLDCM modules allows us to use cheap MOSFET switches, including SiC MOSFET that guarantees operational safety and high efficiency [21,22]. In the traditional TP version, the main disadvantage of a BLDCM is its electromagnetic torque ripple due to the time harmonics of the armature currents that occur during the positional, often six-step, switching of the armature windings [23]. Many methods have been proposed to overcome these ripples, which are widely represented in numerous works. They are associated with the use of special topologies of power semiconductor converters, hybrid, modular, cascade, etc. [24-26], and special advanced methods of switching the armature winding of the machine [27-29]. The electromagnetic torque ripple of the modular multiple TP BLDC drive, to the best of the authors' knowledge, has not been studied in detail. The influence of certain factors in such drives contributes to both the increasing and decreasing of the electromagnetic torque ripples produced by the separate machine modules. However, the total electromagnetic torque ripple can be much lower compared to a single-winding TP machine.

In this work, the ripple levels of the electromagnetic torque of BLDCMs with different modularity of their TP armature windings were investigated by mathematical modeling and computer simulation in the Matlab/Simulink environment. The accuracy of created models is verified by means of comparing the simulation results with ones obtained experimentally for a Dual Three-Phase (DTP) BLDC drive. The influence of various factors on the electromagnetic torque ripple of the modular BLDCM, in particular the degree of modularity, the magnetic coupling between armature winding sets, and drive operation in open and closed-loop control systems, is analyzed. The obtained results allow evaluating and comparing the ripples of the electromagnetic torque produced by separate modules and whole PM motors in different design variants and operating conditions of modular BLDC drives. Based on this, recommendations for building effective multiple TP BLDC drives for EVs are formulated and further research directions are outlined.

The main contribution of this paper consists in the following: (i) the development of simple and at the same time sufficiently accurate mathematical models of multiple TP PM machines; (ii) the creation of high-speed computer models of BLDC drives with different 
degrees of modularity; and (iii) relative estimation of the total electromagnetic torque ripple of modular BLDC drives for operating in open and closed control systems and in the cases of absence and presence of magnetic couplings between the armature winding sets of modular PM machines.

This paper is organized in the following way. Section 2 describes the design features of multiple TP PM motors and highlights the system configuration of BLDC drives of different levels of modularity. Circular mathematical models of the modular BLDCMs are presented in Section 3. In Section 4, the developed computer models of the Single Three-Phase (STP), DTP, Triple Three-Phase (TTP), and Quadruple Three-Phase (QTP) BLDC drives in the Matlab/Simulink software are described. Obtained simulation results of multiple TP BLDC drives operation are shown in Section 5. Section 6 is devoted to the experimental verification of the DTP BLDC drive model. In Section 7, the obtained results are discussed in detail. Conclusions are presented in Section 8.

\section{Design Features of Multiple TP PM Machines and Configuration of Modular BLDC Drives}

Like other types of electric machines, modular BLDCM can have a different number of individual machine modules of different phases, but most modules are made in three phases, and their number does not exceed four [7]. Machine modules can be completely separated in space, e.g., be placed on multiple stators. Then the magnetic coupling between the individual modules is absent, and the operation of the modules is completely independent, which simplifies control and reduces the electromagnetic torque ripple [30]. However, this configuration has much lower specific values (per unit of mass and volume) of power and torque. In magnetically coupled machine modules, the sets of the armature winding are placed on the common magnetic circuit, and such machine is characterized by much higher specific power [31]. In this case, there are mutual influences of the individual modules of the machine on each other that lead to generation of additional higher harmonics of currents and, accordingly, to the increase in the electromagnetic torque ripple of the BLDCM [32]. To reduce these negative effects, various measures are applied, which concern the types of armature windings and the nature of their placement both within its set and in relation to other sets.

In order to implement a large number of individual phase windings and reduce losses in their winding ends, in modular BLDCM, it is advisable to use concentrated windings with non-intersecting winding ends. In this case, to reduce a cogging torque, it will be effective to use the fractional ratio of the number of slots per pole and phase [33]. Fractionalslot concentrated winding has a number of advantages over distributed windings in traditional electric machines, such as high winding factor, high copper packing factor, and hence, high efficiency, reduction in the likelihood of an interphase fault, and extremely low cogging torque [34]. However, fractional-slot windings still generate a large number of space harmonics in the stator magnetic move force (MMF), which rotate at different speeds relative to the rotor and hence cause many undesirable effects that include additional losses, acoustic noise, and vibrations.

The spatial arrangement of the stator winding sets in a modular AC machine may be different: with the alternation of the phases of the same name of each set, with the sectoral arrangement of each set, and so on. Each of these solutions has its advantages and disadvantages [35]. However, the direction of the first harmonic MMF vectors of the armature winding sets is crucial. They can coincide in direction (symmetrical configuration) or be shifted by a certain angle (asymmetrical configuration) $[6-8,10,12]$. The multiple TP BLDCM of symmetrical configuration has all the advantages of modularity except the reduction of current and electromagnetic torque ripple. One can also obtain the latter useful property in a machine of asymmetric configuration. Herewith, it can have two TP 
sets-DTP [12], three TP sets-TTP [36], or four TP sets-QTP [37] of armature winding. The offset angle between these TP sets should be

$$
\gamma=\frac{\pi}{3 i}
$$

where $i$ is the number of TP sets of the armature winding.

Figure 1 shows the spatial arrangement of the vectors of the first harmonic of the PM flux linkage of two sets of the armature winding for the DTP machines of symmetrical and asymmetrical configurations. The asymmetric DTP machine has two TP sets of the armature winding with spatially shifted by $30^{\circ}$ el. and isolated neutral points that eliminate the electromagnetic torque ripple of the sixth harmonic [38].

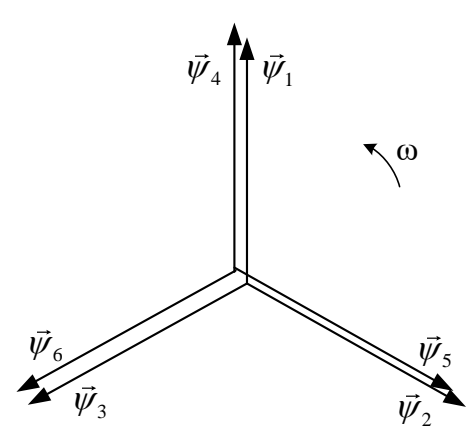

(a)

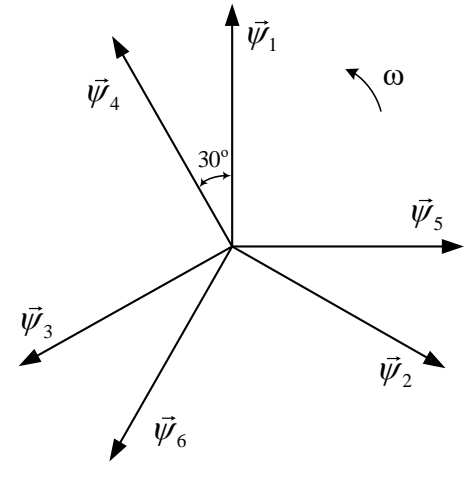

(b)

Figure 1. Vectors of the first harmonic of the PM flux linkage of two armature winding sets for DTP PM machines of symmetrical (a) and asymmetrical (b) configurations.

Figure 2 shows a general scheme of the studied modular BLDC drives with PM machines having a different number of machine modules of asymmetric configuration (shown in different colors), which are offset by the angle $\gamma(1)$. In the scheme, module 1 is the TP armature winding set 1-2-3 is connected to the voltage source inverter VSI1, which is powered by the battery B1; module 2 is the TP armature winding set 4-5-6 is connected to the VSI2, which is powered by the battery B2; module 3 is the TP armature winding set 7-8-9 is connected to the VSI3, which is powered by the battery B3; module 4 is the TP armature winding set 10-11-12 is connected to the VSI4, which is powered by the battery B4.

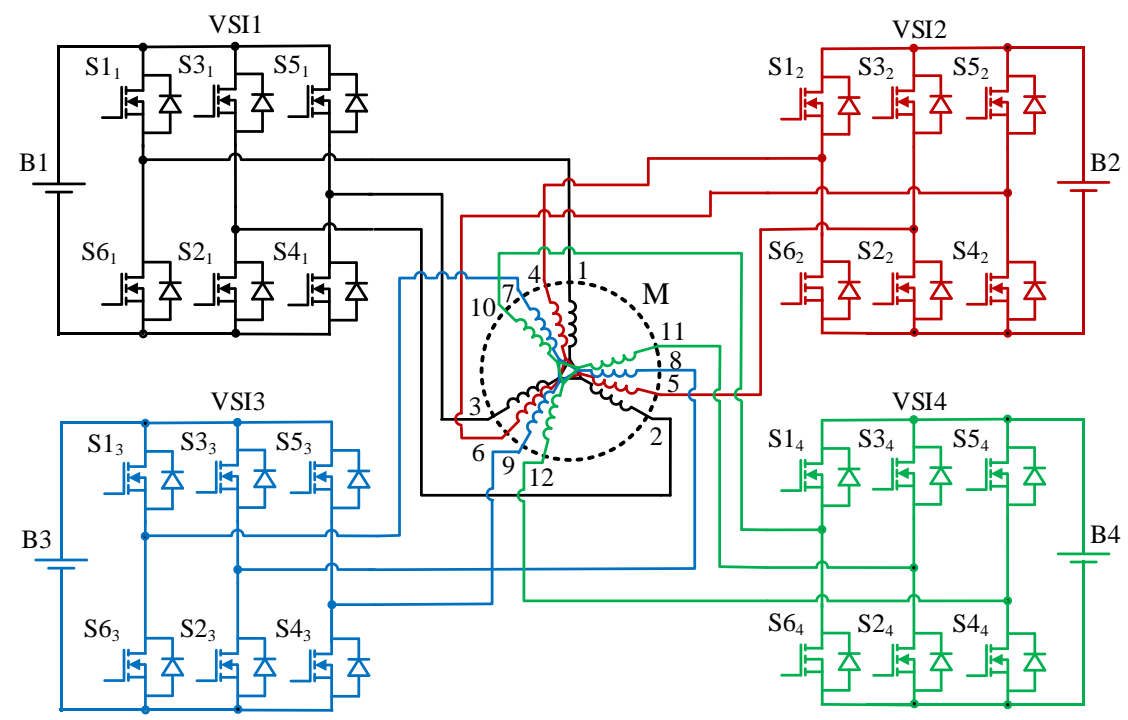

Figure 2. Power circuit of the investigated BLDC drives with different number of machine modules of asymmetrical configuration. 
Further, the modular BLDC drives with DTP, TTP, and QTP PM machines of asymmetrical configuration with the same nominal output parameters in comparison with the traditional BLDC drive with the same parameters, but the PM machine with one TP winding-Single Three-Phase (STP) PM machine, will be investigated.

The sequence of steps of the proposed method for investigating the multiple TP BLDC drives is presented in a flowchart in Figure 3.

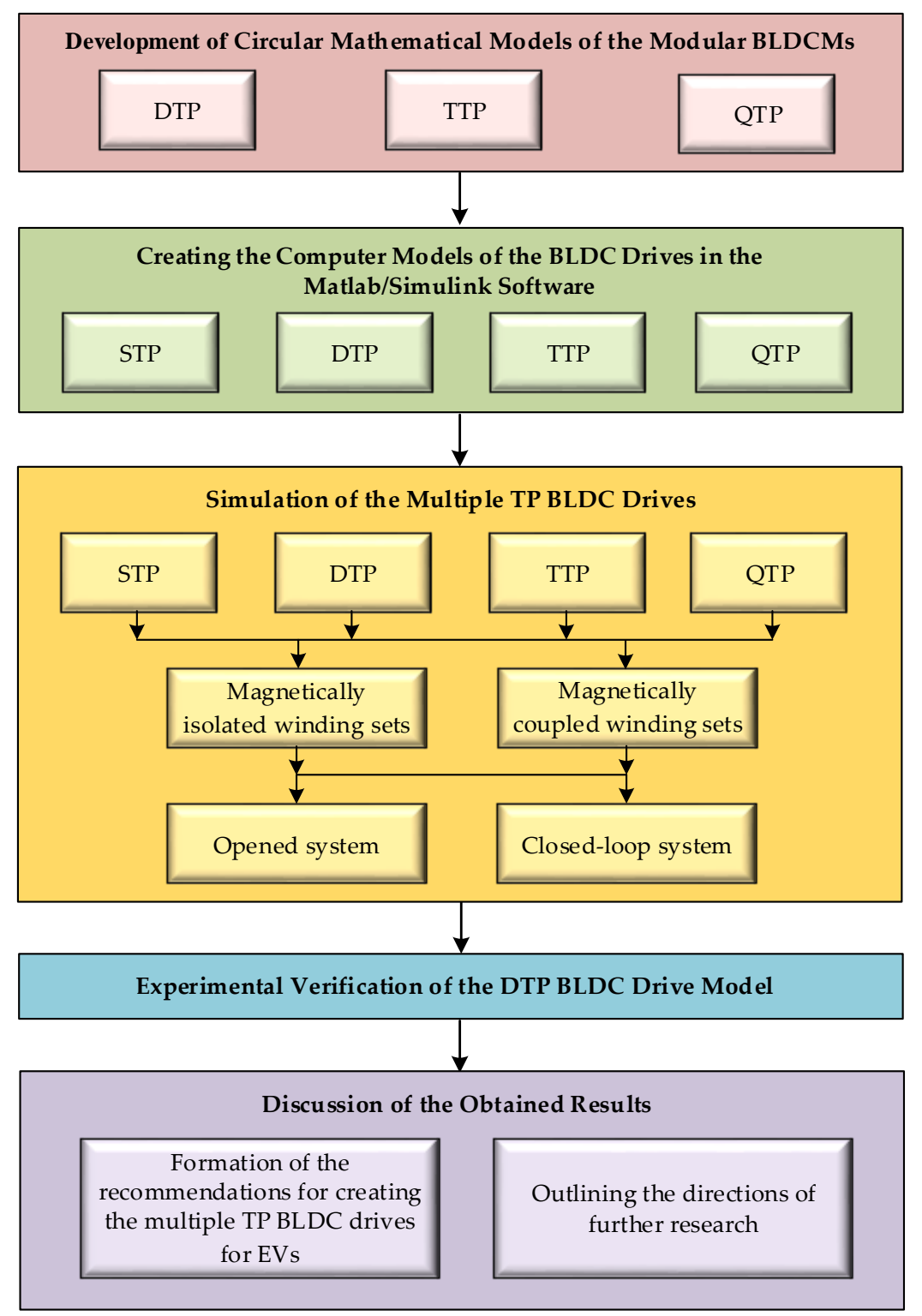

Figure 3. Flowchart of the proposed research method.

\section{Circular Mathematical Models of the Modular BLDCMs}

In order to develop and study modular BLDC drives, it is necessary to develop sufficiently accurate and at the same time rapidly calculating mathematical models that describe electromagnetic processes in modular PM electric machines. Since these machines will work in the BLDC drive system, their operation should be modeled in the phase reference frame. The solutions will be based on the obtained results of finite elements (FE) modeling of magnetic field of the DTP PM machine [38].

In the created mathematical model, we have accepted the following assumptions:

- The mathematical models of multiple TP BLDC drives are based on the improved well-known model of BLDCM in the phase reference frame with static inductances. 
- Static self and mutual inductances are assumed to be constant and independent of currents.

- The mutual inductive coupling between the phases belonging to one set of the armature winding is absent, and between the phases belonging to different sets may have different magnitude and sign depending on the angular displacement between the phase pairs.

- The dependences of the self and mutual inductances on the angular position of the rotor are not taken into account because the studied PM machines do not have a sufficient polarity.

- The shape of the rotation electric move forces (EMF) consists of only the two largest harmonics-the first and the third.

- All machine modules and their magnetic circuits are symmetrical.

- Losses in steel and PMs are neglected.

- The influence of the cogging component of the torque is not taken into account.

Under these assumptions, the voltage equilibrium in all phase circuits of the modular armature winding is described by the following vector-matrix equation:

$$
\overrightarrow{\mathrm{v}}=\mathbf{R} \overrightarrow{\mathrm{i}}+\mathbf{L} \frac{\mathrm{d}}{\mathrm{d} t} \overrightarrow{\mathrm{i}}+\overrightarrow{\mathrm{e}}
$$

where $\vec{v}, \vec{i}, \vec{e}$ are the vectors-columns of the phase voltages, currents, and EMFs, respectively, consisting of a multiple of three elements, for each of the sets of the modular armature winding, $\mathbf{R}$ is the diagonal matrix of identical resistances $R$ of the phase winding of each set, and $\mathbf{L}$ is the matrix of static inductances.

Based on the spatial arrangement of the armature winding sets for the DTP PM motor, as is shown in Figure 1b, the matrix $\mathbf{L}$ can be written as

$$
\mathbf{L}=\left[\begin{array}{cccccc}
L_{a} & M_{120} & M_{120} & M_{30} & M_{90} & M_{150} \\
M_{120} & L_{a} & M_{120} & M_{150} & M_{30} & M_{90} \\
M_{120} & M_{120} & L_{a} & M_{90} & M_{150} & M_{30} \\
M_{30} & M_{150} & M_{90} & L_{a} & M_{120} & M_{120} \\
M_{90} & M_{30} & M_{150} & M_{120} & L_{a} & M_{120} \\
M_{150} & M_{90} & M_{30} & M_{120} & M_{120} & L_{a}
\end{array}\right]
$$

where $L_{a}$ is the self inductance of the phase winding of a set and $M_{\chi}$ are the mutual static inductances between the phase windings shifted by an angle $\chi$.

If we assume that the mutual inductance between two identical windings, which are placed coaxially, is $M$, then, for their displacement by the angle $\chi$, the mutual inductance will be

$$
M_{\chi}=M \cos \chi
$$

Given (4), and the fact that the sum of the currents of the phase windings connected to the star in each set is zero, the matrix $\mathbf{L}$ for the DTP machine can be represented as

$$
\mathbf{L}=\left[\begin{array}{cccccc}
L_{a}^{\prime} & 0 & 0 & \frac{\sqrt{3}}{2} M & 0 & -\frac{\sqrt{3}}{2} M \\
0 & L_{a}^{\prime} & 0 & -\frac{\sqrt{3}}{2} M & \frac{\sqrt{3}}{2} M & 0 \\
0 & 0 & L_{a}^{\prime} & 0 & -\frac{\sqrt{3}}{2} M & \frac{\sqrt{3}}{2} M \\
\frac{\sqrt{3}}{2} M & -\frac{\sqrt{3}}{2} M & 0 & L_{a}^{\prime} & 0 & 0 \\
0 & \frac{\sqrt{3}}{2} M & -\frac{\sqrt{3}}{2} M & 0 & L_{a}^{\prime} & 0 \\
-\frac{\sqrt{3}}{2} M & 0 & \frac{\sqrt{3}}{2} M & 0 & 0 & L_{a}^{\prime}
\end{array}\right]
$$

where $L_{a}^{\prime}=L_{a}-M$. 
The values of the self and mutual inductances given in (5) are in good agreement with the results obtained by FE modeling of the magnetic field of the studied DTP PM machine, if we neglect the magnetic saturation and some explicit polarity in this electric machine [38].

The obtained matrix (5) can be represented as the sum of two matrices: $\mathbf{L}_{\mathbf{a}}$, which describes only the self inductances of the phase windings of the winding sets, and $\mathbf{M}$, which describes the mutual inductances:

$$
\mathbf{L}=\mathbf{L}_{\mathbf{a}}+\mathbf{M}=\operatorname{diag}_{6}\left[L_{a}^{\prime}\right]+M\left[\begin{array}{cccccc}
0 & 0 & 0 & 0.866 & 0 & -0.866 \\
0 & 0 & 0 & -0.866 & 0.866 & 0 \\
0 & 0 & 0 & 0 & -0.866 & 0.866 \\
0.866 & -0.866 & 0 & 0 & 0 & 0 \\
0 & 0.866 & -0.866 & 0 & 0 & 0 \\
-0.866 & 0 & 0.866 & 0 & 0 & 0
\end{array}\right]
$$

Similar to the DTP PM machine, for the TTP PM machine, based on the spatial arrangement of the MMFs of its three sets of the armature winding shown in Figure 4a, the matrix $\mathbf{L}$ can be written as

$$
\mathbf{L}=\left[\begin{array}{ccccccccc}
L_{a} & M_{120} & M_{120} & M_{20} & M_{100} & M_{140} & M_{40} & M_{80} & M_{160} \\
M_{120} & L_{a} & M_{120} & M_{140} & M_{20} & M_{100} & M_{160} & M_{40} & M_{80} \\
M_{120} & M_{120} & L_{a} & M_{100} & M_{140} & M_{20} & M_{80} & M_{160} & M_{40} \\
M_{20} & M_{140} & M_{100} & L_{a} & M_{120} & M_{120} & M_{20} & M_{100} & M_{140} \\
M_{100} & M_{20} & M_{140} & M_{120} & L_{a} & M_{120} & M_{140} & M_{20} & M_{100} \\
M_{140} & M_{100} & M_{20} & M_{120} & M_{120} & L_{a} & M_{100} & M_{140} & M_{20} \\
M_{40} & M_{160} & M_{80} & M_{20} & M_{140} & M_{100} & L_{a} & M_{120} & M_{120} \\
M_{80} & M_{40} & M_{160} & M_{100} & M_{20} & M_{140} & M_{120} & L_{a} & M_{120} \\
M_{160} & M_{80} & M_{40} & M_{140} & M_{100} & M_{20} & M_{120} & M_{120} & L_{a}
\end{array}\right]
$$

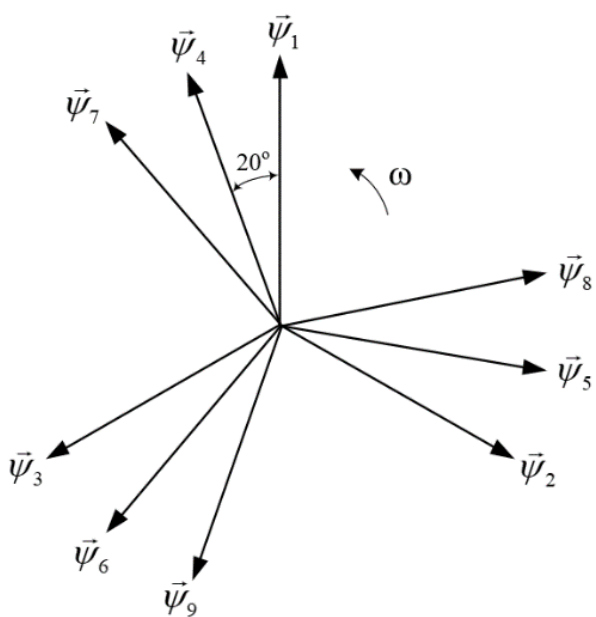

(a)

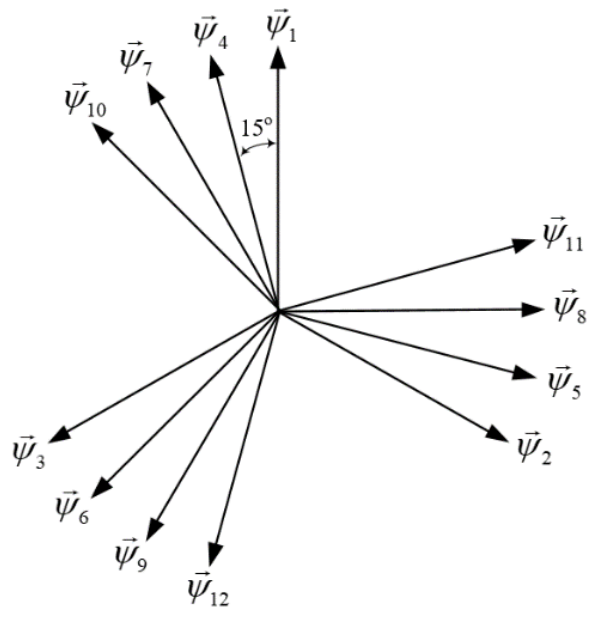

(b)

Figure 4. Vectors of the first harmonic of the PM flux linkages for: (a) three sets of the armature winding for the TTP PM machine, (b) four sets of the armature winding for the QTP PM machine.

Given (4), and the fact that the sum of the currents of the phase windings connected to the star in each set is zero, the matrix (7) for the TTP machine can be represented as 


$$
\mathbf{L}=\operatorname{diag}_{9}\left[L_{a}^{\prime}\right]+M\left[\begin{array}{ccccccccc}
0 & 0 & 0 & 0.940 & -0.174 & -0.766 & 0.766 & 0.174 & -0.940 \\
0 & 0 & 0 & -0.766 & 0.940 & -0.174 & -0.940 & 0.766 & 0.174 \\
0 & 0 & 0 a & -0.174 & -0.766 & 0.940 & 0.174 & -0.940 & 0.766 \\
0.940 & -0.766 & -0.174 & 0 & 0 & 0 & 0.940 & -0.174 & -0.766 \\
-0.174 & 0.940 & -0.766 & 0 & 0 & 0 & -0.766 & 0.940 & -0.174 \\
-0.766 & -0.174 & 0.940 & 0 & 0 & 0 & -0.174 & -0.766 & 0.940 \\
0.766 & -0.940 & 0.174 & 0.940 & -0.766 & -0.174 & 0 & 0 & 0 \\
0.174 & 0.766 & -0.940 & -0.174 & 0.940 & -0.766 & 0 & 0 & 0 \\
-0.940 & 0.174 & 0.766 & -0.766 & -0.174 & 0.940 & 0 & 0 & 0
\end{array}\right]
$$

Similar to the previous two machines, for the QTP PM machine, based on the spatial arrangement of the MMFs of its four sets of the armature winding shown in Figure $4 \mathrm{~b}$, the matrix L can be written as

$$
\mathbf{L}=\left[\begin{array}{cccccccccccc}
L_{a} & M_{120} & M_{120} & M_{15} & M_{105} & M_{135} & M_{30} & M_{90} & M_{150} & M_{45} & M_{75} & M_{165} \\
M_{120} & L_{a} & M_{120} & M_{135} & M_{15} & M_{105} & M_{150} & M_{30} & M_{90} & M_{165} & M_{45} & M_{75} \\
M_{120} & M_{120} & L_{a} & M_{105} & M_{135} & M_{15} & M_{90} & M_{150} & M_{30} & M_{75} & M_{165} & M_{45} \\
M_{15} & M_{135} & M_{105} & L_{a} & M_{120} & M_{120} & M_{15} & M_{105} & M_{135} & M_{30} & M_{90} & M_{150} \\
M_{105} & M_{15} & M_{135} & M_{120} & L_{a} & M_{120} & M_{135} & M_{15} & M_{105} & M_{150} & M_{30} & M_{90} \\
M_{135} & M_{105} & M_{15} & M_{120} & M_{120} & L_{a} & M_{105} & M_{135} & M_{15} & M_{90} & M_{150} & M_{30} \\
M_{30} & M_{150} & M_{90} & M_{15} & M_{135} & M_{105} & L_{a} & M_{120} & M_{120} & M_{15} & M_{105} & M_{135} \\
M_{90} & M_{30} & M_{150} & M_{105} & M_{15} & M_{135} & M_{120} & L_{a} & M_{120} & M_{135} & M_{15} & M_{105} \\
M_{150} & M_{90} & M_{30} & M_{135} & M_{105} & M_{15} & M_{120} & M_{120} & L_{a} & M_{105} & M_{135} & M_{15} \\
M_{45} & M_{165} & M_{75} & M_{30} & M_{150} & M_{90} & M_{15} & M_{135} & M_{105} & L_{a} & M_{120} & M_{120} \\
M_{75} & M_{45} & M_{165} & M_{90} & M_{30} & M_{150} & M_{105} & M_{15} & M_{135} & M_{120} & L_{a} & M_{120} \\
M_{165} & M_{75} & M_{45} & M_{150} & M_{90} & M_{30} & M_{135} & M_{105} & M_{15} & M_{120} & M_{120} & L_{a}
\end{array}\right]
$$

Given (4), as well as the fact that the sum of the currents of the phase windings connected to the star in each section is equal to zero, the matrix (9) can be represented as

$$
\begin{aligned}
& \mathbf{L}=\operatorname{diag}_{12}\left[L_{a}^{\prime}\right]+ \\
& M\left[\begin{array}{cccccccccccc}
0 & 0 & 0 & 0.966 & -0.259 & -0.707 & 0.866 & 0 & -0.866 & 0.707 & 0.259 & -0.966 \\
0 & 0 & 0 & -0.707 & 0.966 & -0.259 & -0.866 & 0.866 & 0 & -0.966 & 0.707 & 0.259 \\
0 & 0 & 0 & -0.259 & -0.707 & 0.966 & 0 & -0.866 & 0.866 & 0.259 & -0.966 & 0.707 \\
0.966 & -0.707 & -0.259 & 0 & 0 & 0 & 0.966 & -0.259 & -0.707 & 0.866 & 0 & -0.866 \\
-0.259 & 0.966 & -0.707 & 0 & 0 & 0 & -0.707 & 0.966 & -0.259 & -0.866 & 0.866 & 0 \\
-0.707 & -0.259 & 0.966 & 0 & 0 & 0 & -0.259 & -0.707 & 0.966 & 0 & -0.866 & 0.866 \\
0.866 & -0.866 & 0 & 0.966 & -0.707 & -0.259 & 0 & 0 & 0 & 0.966 & -0.259 & -0.707 \\
0 & 0.866 & -0.866 & -0.259 & 0.966 & -0.707 & 0 & 0 & 0 & -0.707 & 0.966 & -0.259 \\
-0.866 & 0 & 0.866 & -0.707 & -0.259 & 0.966 & 0 & 0 & 0 & -0.259 & -0.707 & 0.966 \\
0.707 & -0.966 & 0.259 & 0.866 & -0.866 & 0 & 0.966 & -0.707 & -0.259 & 0 & 0 & 0 \\
0.259 & 0.707 & -0.966 & 0 & 0.866 & -0.866 & -0.259 & 0.966 & -0.707 & 0 & 0 & 0 \\
-0.966 & 0.259 & 0.707 & -0.866 & 0 & 0.866 & -0.707 & -0.259 & 0.966 & 0 & 0 & 0
\end{array}\right]
\end{aligned}
$$

The electromagnetic torque of the DTP, TTP, and QTP PM machines can be expressed as

$$
T_{e}=\frac{(\overrightarrow{\mathrm{e}} \cdot \overrightarrow{\mathrm{i}})}{\omega}
$$


where $(\overrightarrow{\mathrm{e}} \cdot \overrightarrow{\mathrm{i}})$ is the dot product of the EMF and armature current vectors.

For the single-mass mechanical system with the moment of inertia $J_{\Sigma}$ reduced to the motor shaft, the equation of motion of the drive has the form

$$
J_{\Sigma} \frac{\mathrm{d} \omega}{\mathrm{d} t}=T_{e}-T_{L}-b \omega
$$

where $T_{L}$ is the load torque of the drive and $b$ is the coefficient of viscous friction.

The position angle of the motor rotor is determined by integrating the angular velocity at zero initial conditions:

$$
\theta=\int \omega \mathrm{d} t
$$

The parameters of the vector elements of the voltage applied to the armature windings in (2) depend on the method of control of the modular PM machine. In the case of BLDCM with 120-degree of switch conductivity, these parameters change six times over cycle, at different points in time for each of the armature winding sets. Using the switches of the inverters (Figure 2), at each point in time, two phases of each set are connected in series and plugged in to its DC bus, and one phase is disconnected. In this case, during phase switching, the current of the open phase continues to flow through freewheeling diodes and plugged phases. Due to the complexity of the mathematical description of the switching processes of each set of the modular PM machine, mathematical modeling of the modular BLDC drive operation should be performed by computer simulation in the Matlab/Simulink using virtual models of bridge inverters and six-step switching algorithms available in the SimScape library. Such algorithm for BLDC drive based on the DTP PM machine of asymmetrical configuration with the offset of the armature winding sets by $30^{\circ}$ el. is presented in Table 1 . Similar to Table 1 , the corresponding tables for switches conductivity are compiled for the BLDC drives based on the TTP and QTP PM machines with the offsets of the armature windings sets by $20^{\circ}$ el. and $15^{\circ}$ el., respectively.

Table 1. The order of six-step switching of the BLDC drive based on the DTP PM machine of asymmetrical configuration

\begin{tabular}{|c|c|c|c|c|c|c|c|c|c|c|c|c|c|}
\hline \multirow{3}{*}{$\theta\left({ }^{\circ} \mathrm{el}.\right)$} & \multicolumn{12}{|c|}{ Switching States } & \multirow{3}{*}{$\theta\left({ }^{\circ} \mathrm{el}.\right)$} \\
\hline & \multicolumn{6}{|c|}{ VSI1 } & \multicolumn{6}{|c|}{ VSI2 } & \\
\hline & $\mathrm{S} \mathbf{1}_{1}$ & $S 2_{1}$ & $\mathrm{~S} 3_{1}$ & $S 4_{1}$ & $\mathrm{~S} 5_{1}$ & $S 6_{1}$ & $\mathrm{S1}_{2}$ & $\mathrm{~S} 2_{2}$ & $\mathrm{~S}_{2}$ & $\mathrm{~S}_{2}$ & $\mathrm{~S}_{2}$ & $\mathrm{~S}_{2}$ & \\
\hline $0-30$ & \multirow{2}{*}{1} & \multirow{2}{*}{1} & \multirow{2}{*}{0} & \multirow{2}{*}{0} & \multirow{2}{*}{0} & \multirow{2}{*}{0} & 1 & 1 & 0 & 0 & 0 & 0 & $0-30$ \\
\hline $30-60$ & & & & & & & \multirow{2}{*}{1} & \multirow{2}{*}{0} & \multirow{2}{*}{0} & \multirow{2}{*}{1} & \multirow{2}{*}{0} & \multirow{2}{*}{0} & $30-60$ \\
\hline $60-90$ & \multirow{2}{*}{1} & \multirow{2}{*}{0} & \multirow{2}{*}{0} & \multirow{2}{*}{1} & \multirow{2}{*}{0} & \multirow{2}{*}{0} & & & & & & & $60-90$ \\
\hline $90-120$ & & & & & & & 0 & 0 & 1 & 1 & 0 & 0 & $90-120$ \\
\hline $120-150$ & \multirow{2}{*}{0} & \multirow{2}{*}{0} & \multirow{2}{*}{1} & \multirow{2}{*}{1} & \multirow{2}{*}{0} & \multirow{2}{*}{0} & & & & & & & $120-150$ \\
\hline $150-180$ & & & & & & & 0 & 0 & 1 & 0 & 0 & 1 & $150-180$ \\
\hline $180-210$ & \multirow{2}{*}{0} & \multirow{2}{*}{0} & \multirow{2}{*}{1} & \multirow{2}{*}{0} & \multirow{2}{*}{0} & \multirow{2}{*}{1} & & & & & & & $180-210$ \\
\hline $210-240$ & & & & & & & 0 & 0 & 0 & 0 & 1 & 1 & $210-240$ \\
\hline $240-270$ & 0 & 0 & 0 & 0 & 1 & 1 & & & & & & & $240-270$ \\
\hline $270-300$ & & & & & & & 0 & 1 & 0 & 0 & 1 & 0 & $270-300$ \\
\hline $300-330$ & 0 & 1 & 0 & 0 & 1 & 0 & & & & & & & $300-330$ \\
\hline $330-360$ & & & & & & & 1 & 1 & 0 & 0 & 0 & 0 & $330-360$ \\
\hline
\end{tabular}
with the offset of the armature winding sets by $30^{\circ} \mathrm{el}$. 


\section{Computer Models of the STP, DTP, TTP and QTP BLDC Drives in the Matlab/Simulink Software}

Computer models of the STP, DTP, TTP, and QTP BLDC drives are developed in the Matlab/Simulink environment based on Equations (2)-(13) according to the same approach and differ only in a number of PM machine modules, their parameters, and the implementation of mutual inductive couplings between the armature winding sets.

The parameters of the machine modules were chosen to obtain the same nominal values of the output parameters of the drives-angular velocity, electromagnetic torque, and power (Table 2). The parameters of the experimental DTP PM machine of the fractional slot structure $Z / 2 p_{\mathrm{p}} / i=24 / 20 / 3$ [38] with a nominal DC module voltage of $48 \mathrm{~V}$ were taken as a basis. This voltage of the onboard bus is considered as safe for EVs, so the same battery voltage was taken to power the TTP and QTP BLDC drives. For the BLDC drive based on the STP PM machine, the supply DC voltage was doubled, i.e., 96 V. Because the supply DC voltages of the DTP, TTP, and QTP BLDC drives are the same, it is assumed that their armature winding sets have the same number of turns and, accordingly, the same values of self and mutual inductances, as well as their PM flux linkage. The values of resistances of the armature winding sets $R$ were determined from the condition that for all studied multiple three-phase PM machines the current density $q$ in windings is the same. Substituting in the expression for the phase winding resistance of the cross-sectional area of the wire $S=I / q$, where $I$ is the average value of the current in the phase winding set, and assuming the equal length $l$ of the wire in winding set for three modular machines, we obtain the right dependence

$$
R=\rho \frac{l}{S}=\rho \frac{l q}{I}=\frac{K}{I}
$$

where $\rho$ is the copper resistivity of winding wire and $K=\rho l q=$ const.

Table 2. Parameters of the studied modular BLDC drives.

\begin{tabular}{|c|c|c|c|c|}
\hline \multirow{2}{*}{ Parameters } & \multicolumn{4}{|c|}{ Value } \\
\hline & \multicolumn{4}{|c|}{ for Whole PM Motor } \\
\hline Total rated power, $P_{\mathrm{n}}(\mathrm{W})$ & \multicolumn{4}{|c|}{300} \\
\hline Rated torque, $T_{\mathrm{n}}(\mathrm{Nm})$ & \multicolumn{4}{|c|}{15} \\
\hline Rated angular velosity, $\omega_{\mathrm{n}}\left(\mathrm{s}^{-1}\right)$ & \multicolumn{4}{|c|}{20} \\
\hline Number pair of poles, $p_{\mathrm{p}}$ & \multicolumn{4}{|c|}{10} \\
\hline \multirow[t]{3}{*}{ Moment of inertia, $J_{\sum}\left(\mathrm{kg} \cdot \mathrm{m}^{2}\right)$} & \multicolumn{4}{|c|}{0.1} \\
\hline & \multicolumn{4}{|c|}{ per One Module } \\
\hline & STP & DTP & TTP & QTP \\
\hline Supply DC voltage, $V_{\mathrm{dc}}(\mathrm{V})$ & 96 & 48 & 48 & 48 \\
\hline Rated phase current, $I_{\mathrm{n}}(\mathrm{A})$ & 3.7 & 3.7 & 2.4 & 1.8 \\
\hline Phase winding resistance, $R(\Omega)$ & 0.500 & 0.250 & 0.385 & 0.514 \\
\hline Phase winding self-inductance, $L_{a}(\mathrm{mH})$ & 10.78 & 5.39 & 5.39 & 5.39 \\
\hline Winding mutual inductance, $M(\mathrm{mH})$ & 3.18 & 1.59 & 1.59 & 1.59 \\
\hline Flux linkage by $\mathrm{PM}, \psi_{\mathrm{m}}(\mathrm{Wb})$ & 0.224 & 0.112 & 0.112 & 0.112 \\
\hline
\end{tabular}

Taking the value of $K$ for the experimental DTP PM machine according to the currents in the sets of the armature windings obtained during the simulation and based on (14), the phase resistances of the armature winding sets for the TTP and QTP PM machines were determined as follows and are given in Table 2. The correctness of such approach was confirmed by the same values of efficiency, in which only copper losses were considered, obtained in simulation for all studied modular PM machines.

The structure of computer models of multiple TP BLDC drives will be considered on the example of DTP BLDC drive (Figure 5). The model consists of two similar parts, the subsystems and main blocks, which are marked with indices 1 and 2. Each part includes the electromagnetic subsystem - the PM Machine Module Subsystem, which is switched by 
its six-switch VSI powered from its battery module B. The PWM Subsystem generates the control signals for the VSI switches according to the principle of 120-degree switching based on "pulse" signals produced by the Hall Subsystem based on the information about the angular position of the rotor "angle". Given the asymmetrical configuration of two modules of the armature winding, the switching of the VSI2 is shifted by an angle $\pi / 6$ relative to the VSI1, which ensures the operation of the switches of both inverters in accordance with Table 1. In addition, the PWM Subsystem regulates the output VSI voltage in proportion to the input reference signal by PWM of three lower switches of the inverter because one of these switches always works at the 120-degree control. The BLDC drive operates in a closed two-loop control system with the outer loop of the angular speed control by a proportional speed regulator SR $\left(k_{\mathrm{P}}=10\right)$ and the inner two loops of the current control in each machine module by PI current regulators CR $\left(k_{\mathrm{P}}=10, k_{\mathrm{I}}=500\right)$. For making the current control loop, in this system, the estimated current values of each winding set were obtained by the Current Estimators. The electromagnetic torques generated by two machine modules are added, and the total electromagnetic torque goes to the common mechanical part of the drive, which is implemented in accordance with Equations (9) and (10).

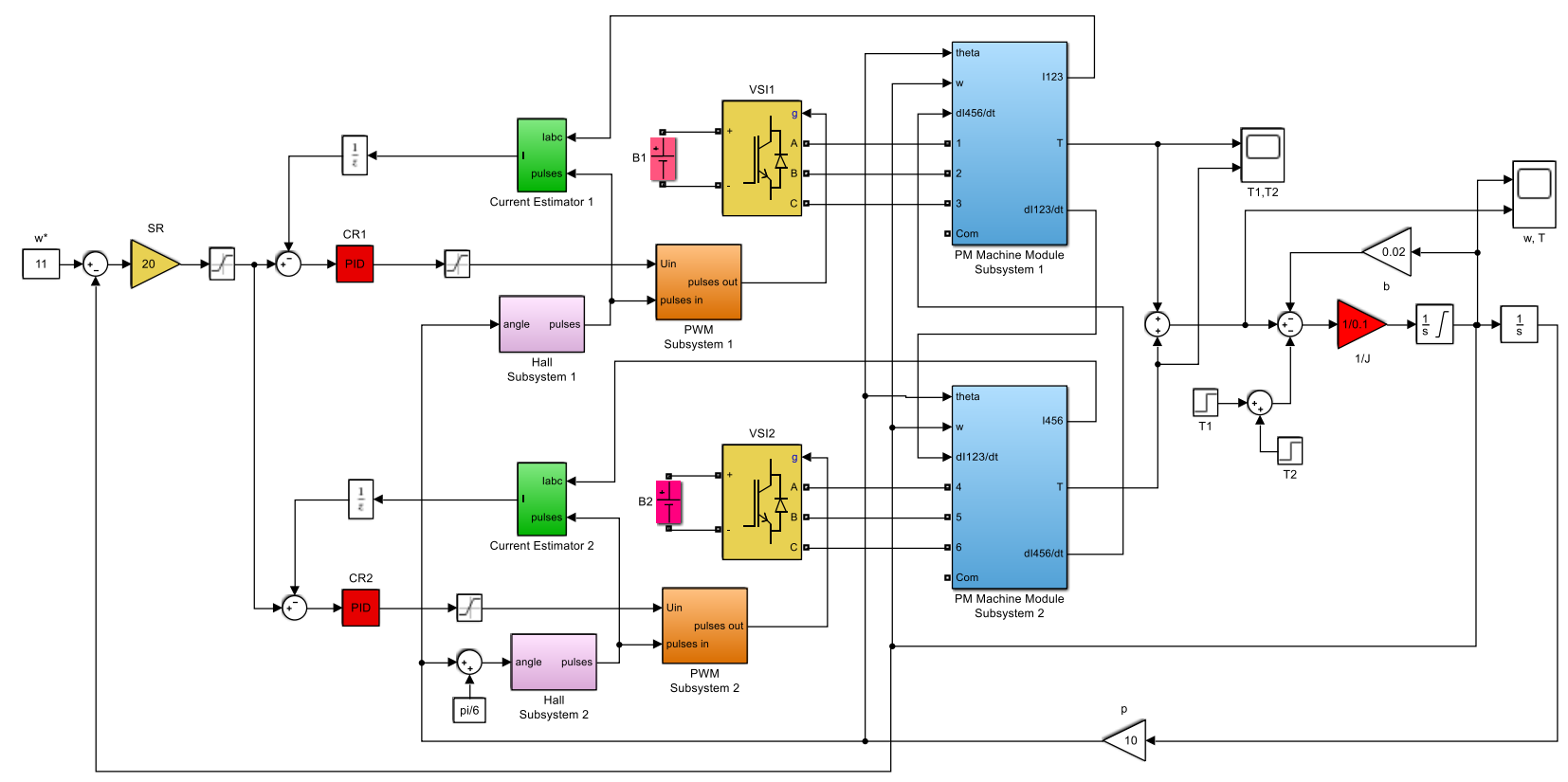

Figure 5. DTP BLDC drive computer model.

\subsection{Model of the Electromagnetic Part of the Studied DTP PM Machine}

The computer model of the electromagnetic part of one DTP PM machine module, which is based on the mathematical model described in Section 3, is presented in Figure 6. Its left part consists of three identical channels, which integrate the equations of voltage balances (2) in the three phases of this winding set according to the equation

$$
\overrightarrow{\mathrm{i}}=\mathbf{L}_{\mathbf{a}}^{-1} \int_{0}^{t}\left(\overrightarrow{\mathrm{v}}-\mathbf{R} \overrightarrow{\mathrm{i}}-\overrightarrow{\mathrm{e}}-\mathbf{M} \frac{\mathrm{d}}{\mathrm{d} t} \overrightarrow{\mathrm{i}}\right) \mathrm{d} t
$$

At the output of each channel, the value of the linear current of this phase is obtained. Three current values form the references for the controlled current sources CCS1-CCS3, which connect the signals of the applied phase voltages to the virtual part of the power supply of the machine module from the VSI. From these voltages, at the input of the channels, the voltage drops on the resistance of the winding $R$, as well as the EMFs of rotation and the EMFs of mutual induction are subtracted according to (15). The values of the latter for three phases are formed in the EMF Subsystem and Mutual Induction Link 
Subsystem, respectively. The flux linkages of self-induction obtained after the integration are divided into their own static inductances. The obtained values of the linear currents are also used to calculate the electromagnetic torque by expression (11). The discrete time derivatives of currents from the output 2 of the module subsystem go to the Mutual Induction Link Subsystem of another module to form there the EMFs of mutual induction.

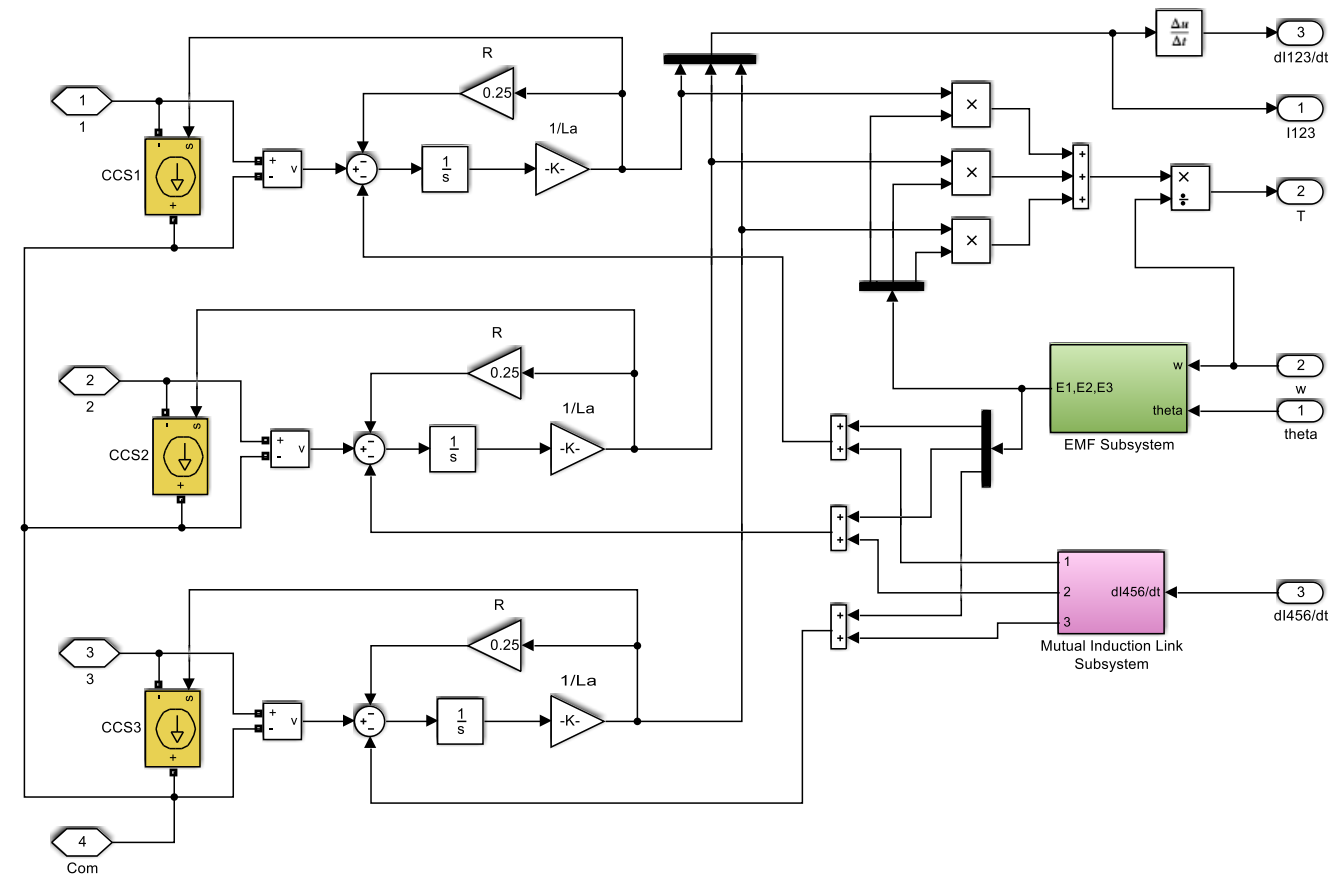

Figure 6. Computer model of the electromagnetic part of the first DTP PM machine module.

In the EMF Subsystem for one machine module shown in Figure 7, three Flux Linkage Shape Subsystems form the angular dependences of the phase flux linkages of the machine at its idle run. For all studied modular PM machines, the phase flux linkages include, in addition to the first harmonic, also a third harmonic of $9.3 \%$, as it was obtained by studying the magnetic field of the experimental DTP PM machine by the FE method [38]. Next, these dependences are multiplied by the current value of the angular frequency " $\mathrm{w}$ " and the amplitude of the flux linkage " $\mathrm{F}$ " at idle run. As a result, the current values of the EMFs of the winding set are obtained in the output of the subsystem.

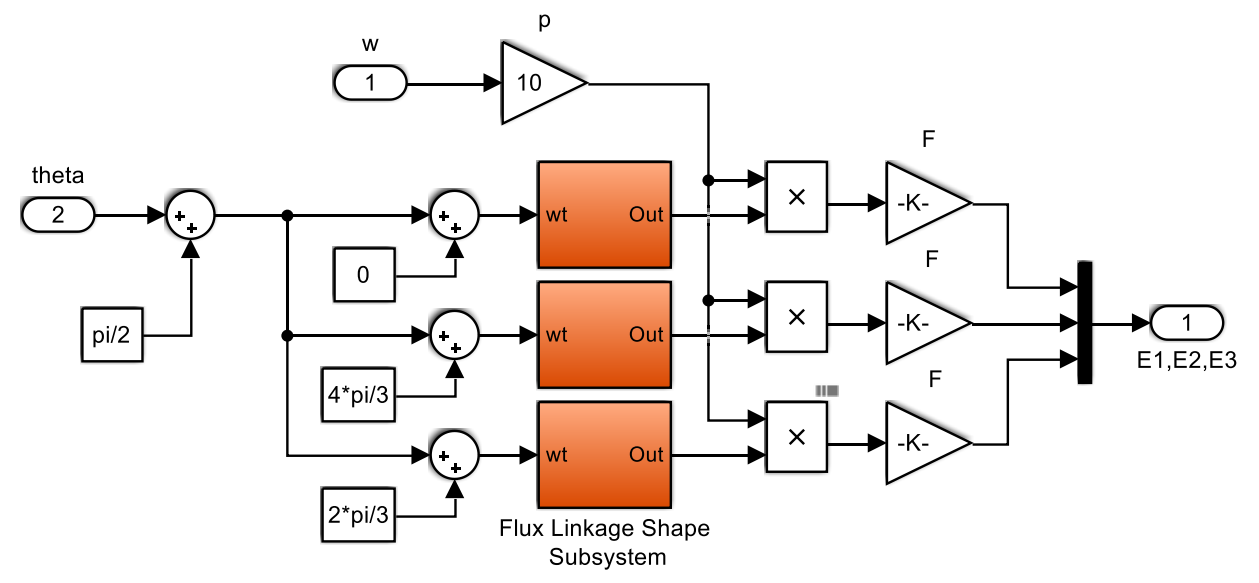

Figure 7. Computer model of the EMF Subsystem for one machine module.

The Mutual Induction Link Subsystem, which is shown in Figure 8 for the first machine module, generates at its output the EMFs of mutual inductance according to (6) for this machine module. 


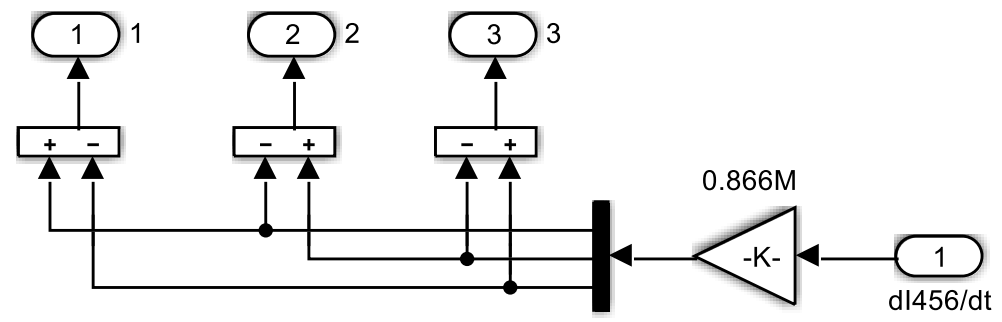

Figure 8. Computer model of the Mutual Induction Link Subsystem for the first module of the DTP PM machine.

The computer model of the electromagnetic part of the second module of the DTP PM machine differs from the similar model of the first module by the shifting on the angle $\pi / 6$ the phase EMFs of rotation in the EMF Subsystem and by the topology of the EMFs of mutual induction according to the matrix $\mathbf{M}$ in (6).

In the computer models of the TTP and QTP BLDC drives, the Mutual Induction Link Subsystems are compiled according to the matrices $\mathbf{M}(8)$ and (10) for the TTP and QTP PM machines, respectively, and are shown in Figure 9.

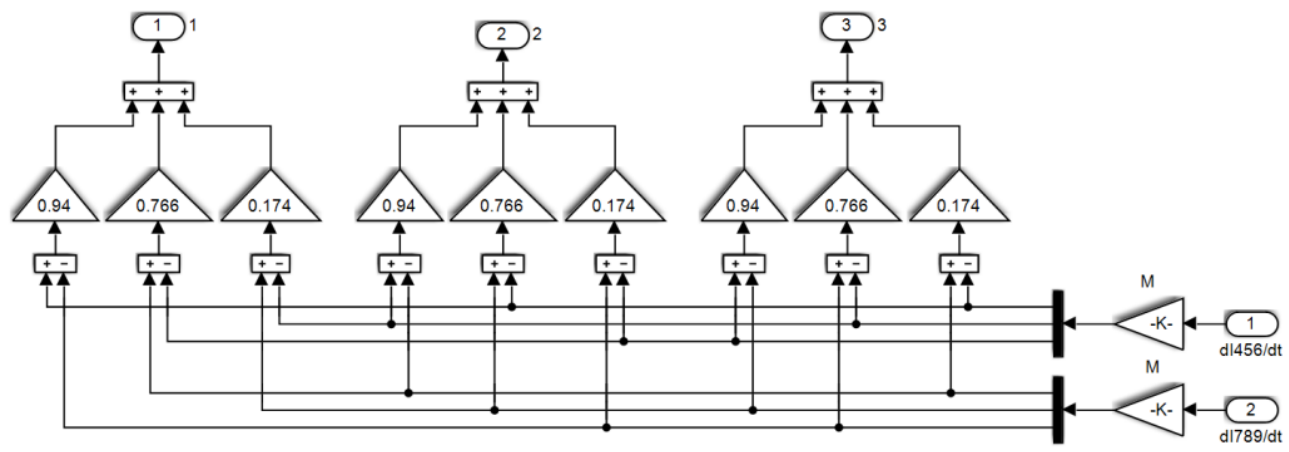

(a)

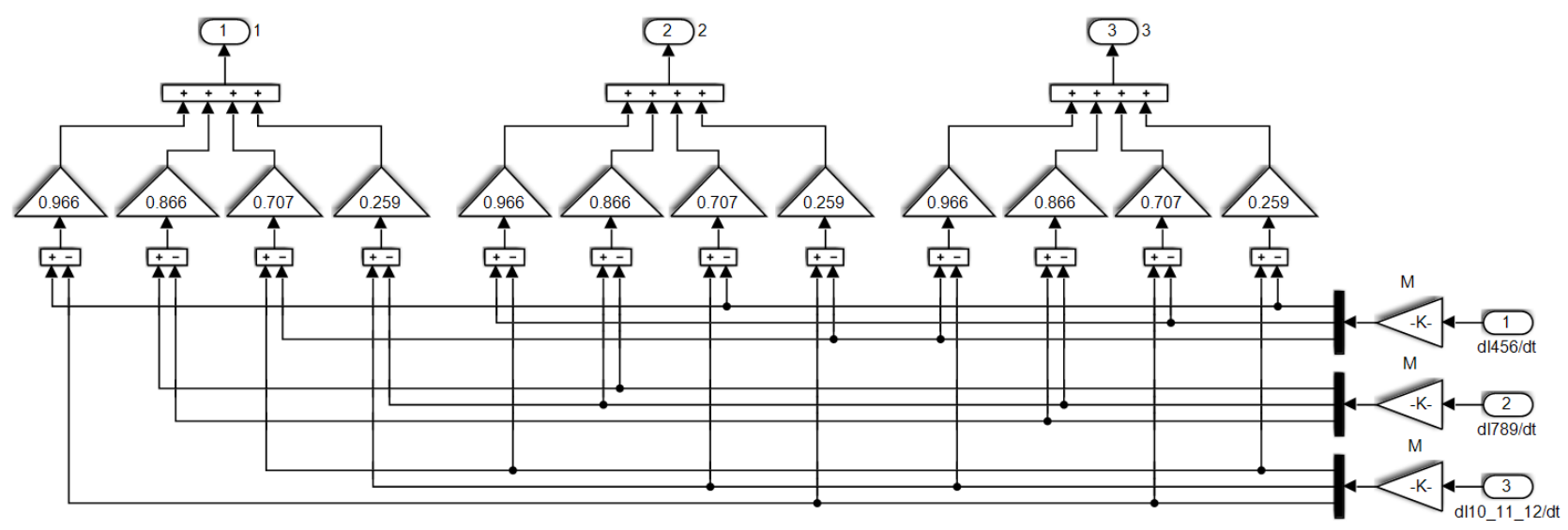

(b)

Figure 9. Computer models of the Mutual Induction Link Subsystem for the first machine module of the TTP (a) and QTP (b) PM machines.

\subsection{Computer Models of Other Major Subsystems}

In Figure 10, the computer model of the Hall Subsystem is shown. First, three-phase symmetric sinusoidal signals are formed from the current value of the angle of the rotor position "angle". The moments of transition of the sinusoidal signals through zero serve as signals for switching three R-S triggers. The required six signals for the control channels of the VSI switches with 120-degree conductivity are formed from the output signals of 
the triggers with the help of logical blocks AND. The Hall Sensor Position block sets the value of the angle, which simulates the position of the Hall sensor system and allows you to synchronize the operation of the VSI with the EMFs of the BLDCM module.

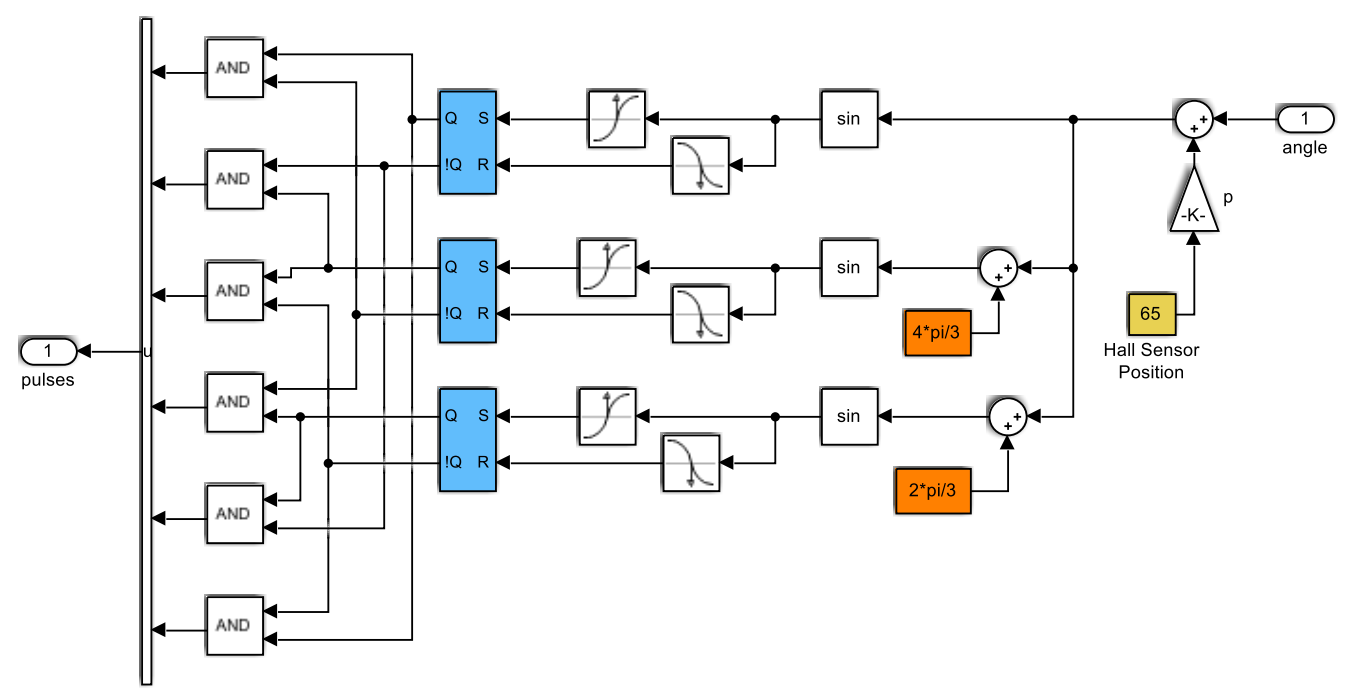

Figure 10. Computer model of the Hall Subsystem.

Figure 11 presents a computer model of the PWM Subsystem, which forms the logic control signals for six-step switch of the VSI with 120 degree of conductivity from the signals of the Hall Subsystem. Depending on the sign of the input control voltage "Uin", three Reverse Subsystems change by $180^{\circ}$ the sequence of control signals of the VSI switches, changing the sign of the electromagnetic torque generated by the BLDCM module to the opposite. In addition, in proportion to the input control voltage, the PWM Subsystem generates three PWM signals, which are logically added to the control signals of three upper switches of the VSI adjusting its output voltages.

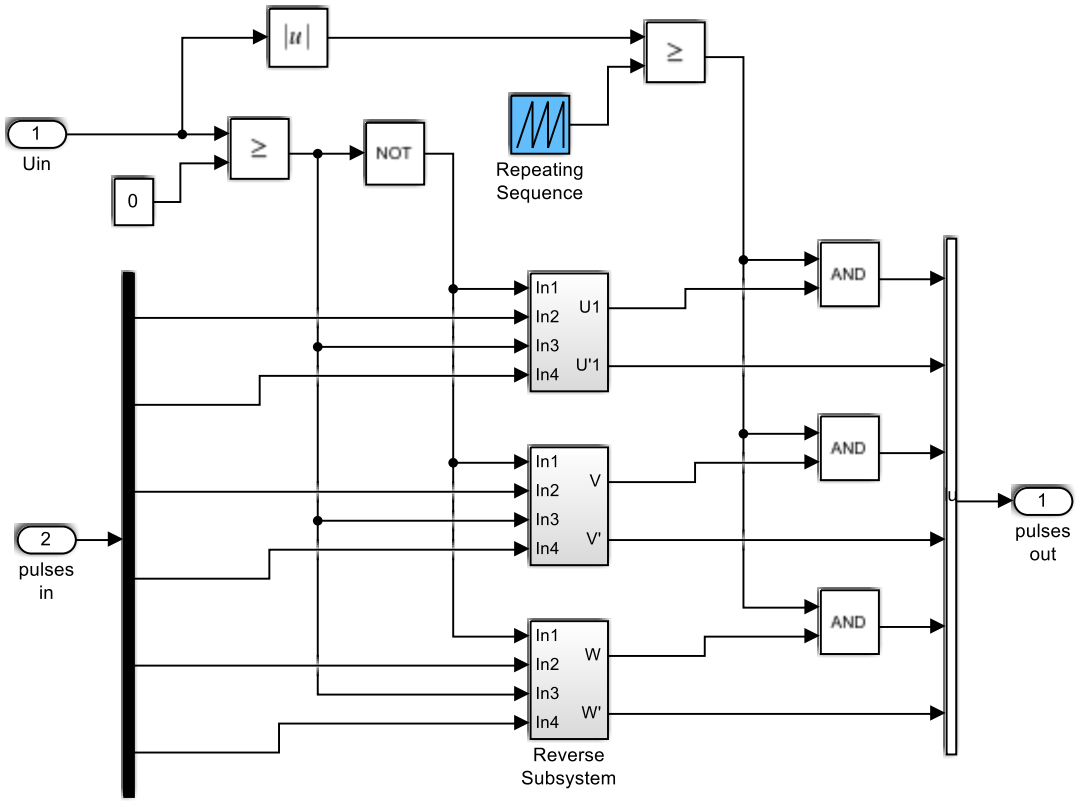

Figure 11. Computer model of the PWM Subsystem.

In Figure 12, a computer model of the Current Estimator is presented. The input signals for this subsystem are the values of three linear currents in the phases of the armature winding module "Iabc" and six logic signal "pulses" from the Hall Subsystem. From the latter, with the help of six logic blocks AND, switching signals are formed for the 
six switches so that the outputs of the first three switches emit positive half-waves of linear currents and the outputs of the other three emit negative ones. After adding the positive currents and subtracting the negative ones at the output of the subsystem, the resulting DC current value of the BLDCM module is obtained, which is used as feedback for automatic regulation of the currents of this module.

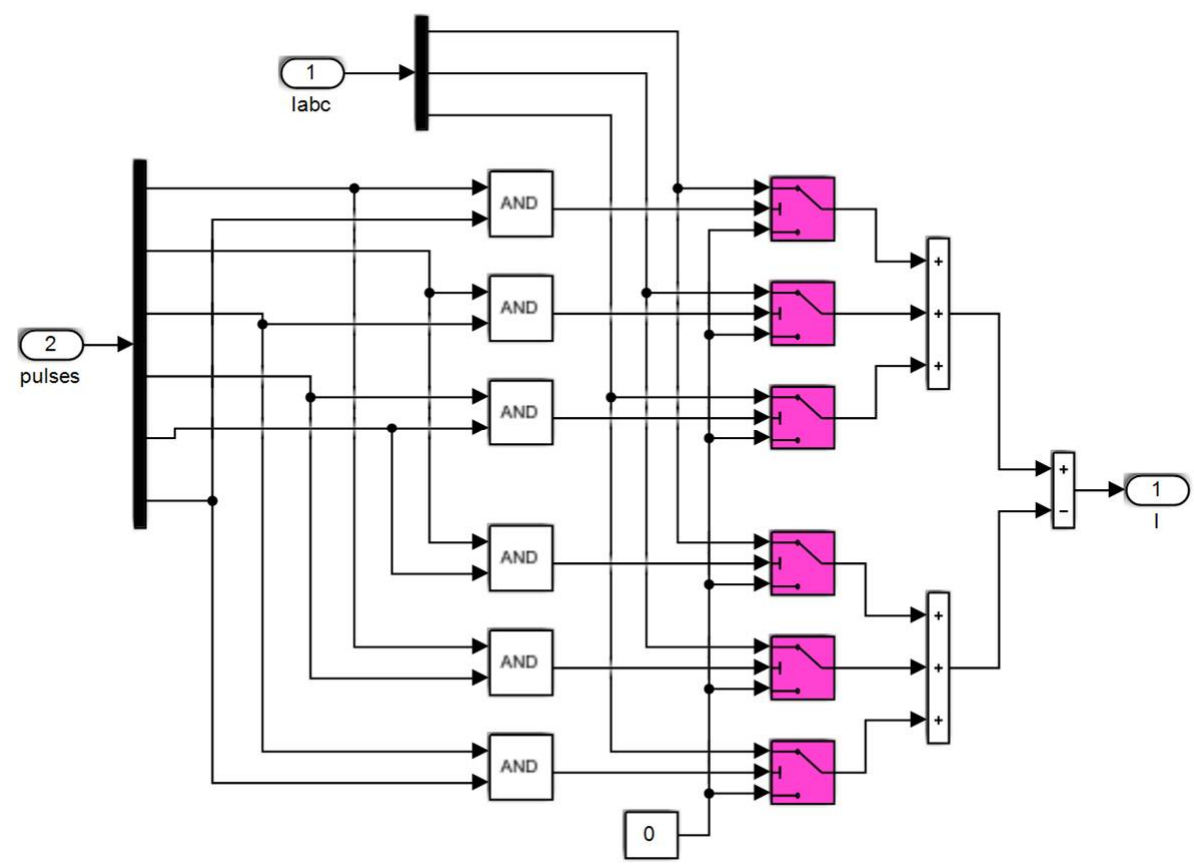

Figure 12. Computer model of the Current Estimator.

\section{Results of Computer Simulation of Multiple TP BLDC Drives}

In this section, in order to assess the influence of magnetic coupling on each type of multiple TP BLDC drive, the results of two series of simulation are presented. The first series shows a variant with magnetically uncoupled sets of the armature windings of multiple TP PM machine, and the second series demonstrates a variant with magnetically coupled ones. All variants were studied under the same conditions. First, by time $0.18 \mathrm{~s}$, the drive worked in a closed two-loop control system, which is described in Section 4. During this time, the BLDCM accelerated to the set rated angular velocity of $20 \mathrm{rad} / \mathrm{s}$, and at a time of $0.13 \mathrm{~s}$, an additional load torque was suddenly applied to the shaft that increased the total load torque to the rated value. Then, at the time of $0.18 \mathrm{~s}$, the control system was opened in order to see the natural shapes of linear currents in the armature winding and to estimate the level of the electromagnetic torque ripple during switching of the armature winding at the fundamental frequency. To exclude PWM from operation, the PWM Subsystem input was supplied with a maximum control voltage of $10 \mathrm{~V}$, which corresponded to the power supply of two series-connected phase armature windings from the full battery voltage. In order not to change the average value of the electromagnetic torque, the power supply of the VSI was switched to another DC supply with slightly lower than the battery nominal voltage, the value of which was found experimentally.

\subsection{STP BLDC Drive}

The STP BLDC drive is considered to be a basic most common option, in which there are no sets of the armature winding, so there can be no magnetic coupling between them. Figure 13 presents the waveforms of the angular velocity and electromagnetic torque of the studied STP BLDC drive obtained in simulation by the model which is shown in Figure 4 but only with one module of PM motor and parameters shown in Table 2. As seen from Figure 13a, the control system provides acceleration of the drive with a reference torque of double compared to the rated value and subsequent stabilization of the angular 
velocity at the given level of $20 \mathrm{rad} / \mathrm{s}$. After opening the control system at the time of $0.18 \mathrm{~s}$, the angular velocity remains at the previous level due to the reduction of the battery voltage from $96 \mathrm{~V}$ to the level of $90.43 \mathrm{~V}$. The electromagnetic torque shown in Figure 13b is characterized by significant switching ripples, which will be analyzed further in Section 7 .

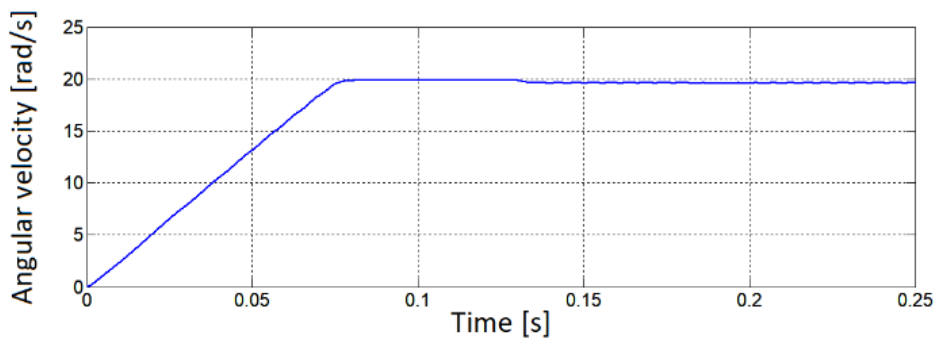

(a)

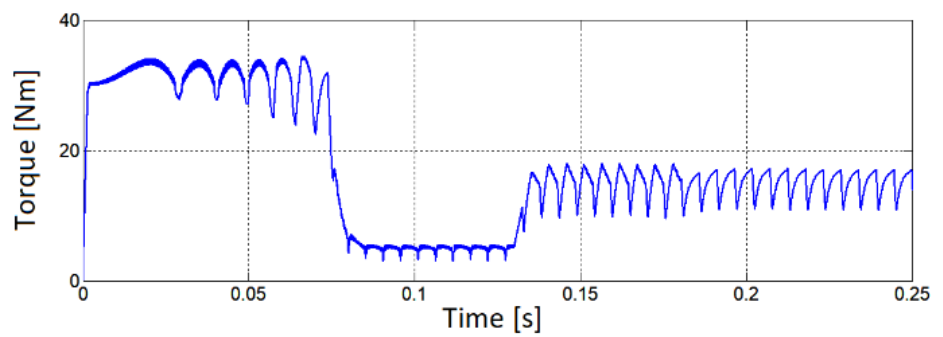

(b)

Figure 13. Waveforms of the output variables of the studied STP BLDC drive: (a) angular velocity and (b) electromagnetic torque.

In Figure 14, the main variables in one phase of the studied STP BLDC drive were presented in a time interval of $0.1 \mathrm{~s}$ in order to assess their shapes. As can be seen in Figure 14a, the phase voltage has a well-known for a BLDC drive shape with ejections through $60^{\circ}$ el. during each switching of the armature winding. Figure $14 \mathrm{~b}$ shows a good synchronization between the EMF and the current that indicates the correct placement of the rotor position sensors.

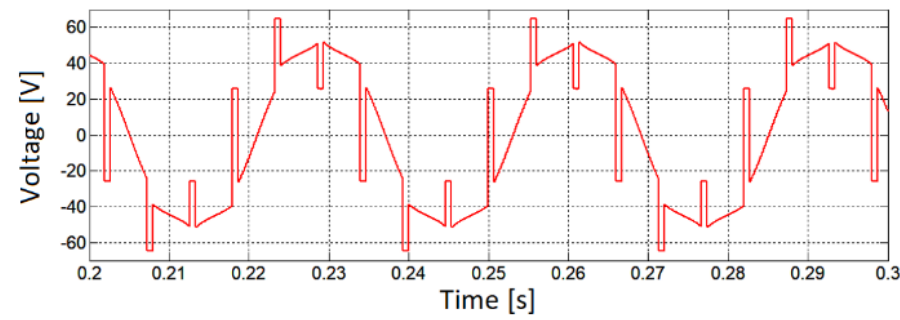

(a)

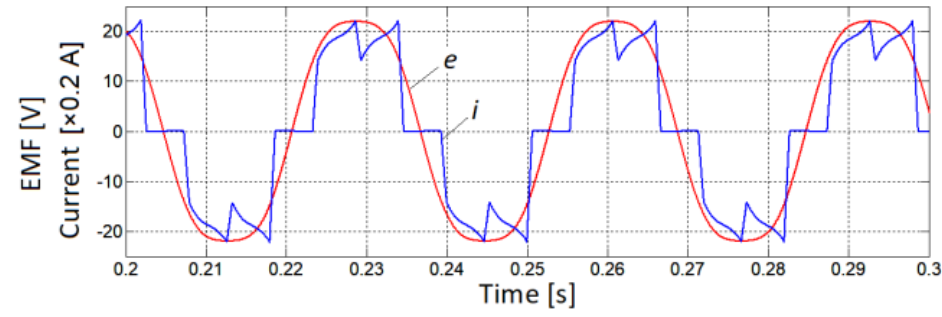

(b)

Figure 14. Shapes of the main variables in one phase of the studied STP BLDC drive at open-loop operation: (a) the voltage and (b) the EMF $e$ (red) and current $i$ (blue). 


\subsection{DTP BLDC Drive}

Figure 15 presents the waveforms of the main variables of the studied DTP BLDC drive obtained in the simulation by the model shown in Figure 5. The parameters of the drive corresponded to those in Table 2. To make the comparison easier, the waveforms of the corresponding variables for cases without and with magnetic coupling between winding sets of the DTP PM machine are placed side by side.
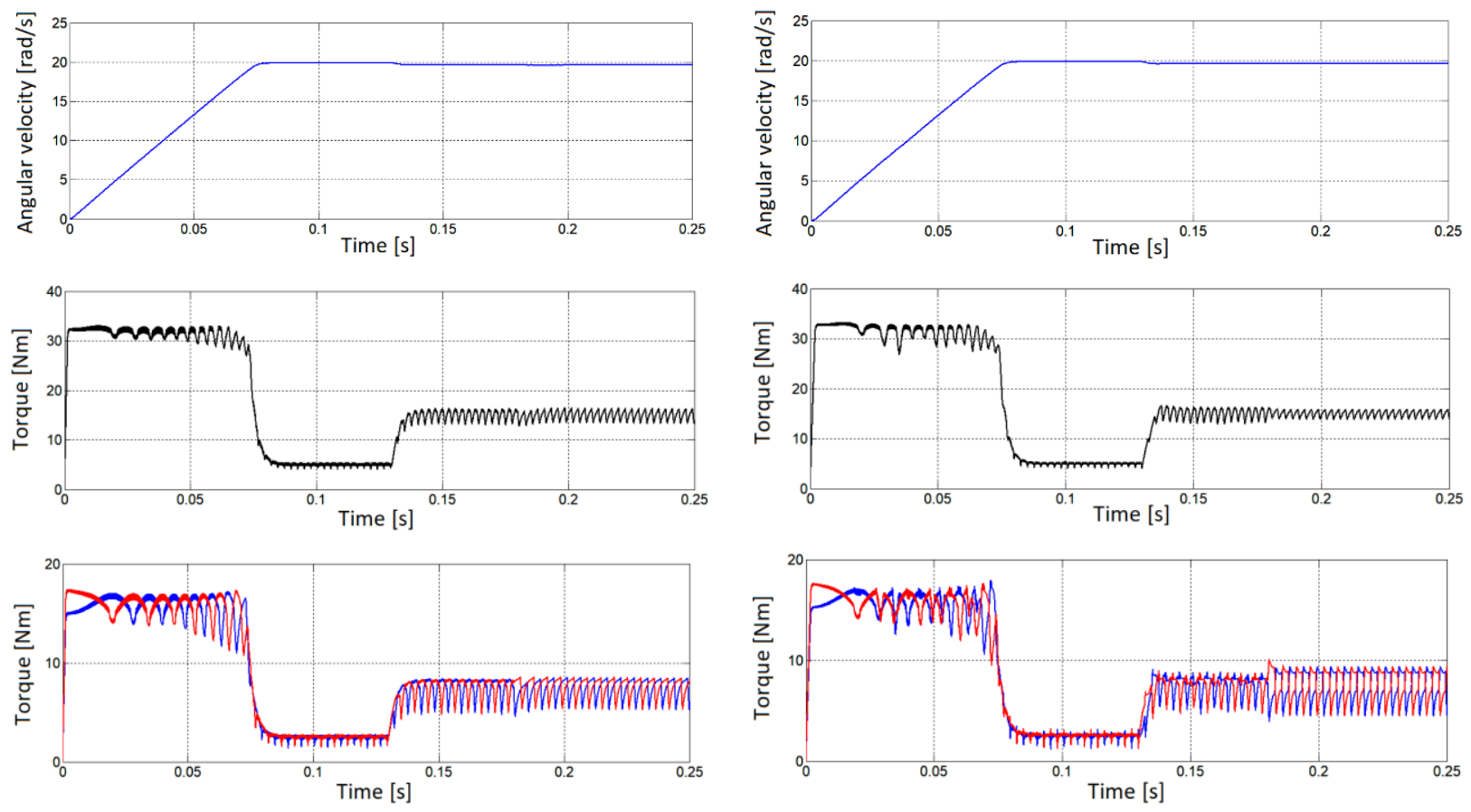

(a)

(b)

Figure 15. Waveforms of the output variables of the studied DTP BLDC drive without (a) and with (b) magnetic coupling between the winding sets: from top to bottom-angular velocity, total electromagnetic torque, electromagnetic torques of two modules (by different colors).

The waveforms of the electromagnetic torque show that both in the case of magnetically unconnected winding sets and in the case of a magnetic coupling between them, the total electromagnetic torque ripple generated by both modules is much smaller than the pulsations of each module. This is due to the optimal angular shift between winding sets in accordance with (1), which leads to a corresponding shift on the half-switching period of the electromagnetic torques created by them and mutual compensation of their pulsations in the total electromagnetic torque.

Similarly to Figure 14, in Figure 16, the waveforms of main variables in one phase of the studied DTP BLDC drive were presented in the same time interval of $0.1 \mathrm{~s}$ but for the cases without and with magnetic coupling between the winding sets of the DTP PM machine. As can be seen from Figure 16b, the characteristic switching ejections in phase voltage for the case of magnetically coupled winding sets have twice the frequency compared to magnetically uncoupled winding sets (Figure 16a). This is due to the induction in each of the winding set of the switching self-induction EMF of the other set due to the magnetic coupling between them. This effect of one winding set to another generates additional pulsations in the current curve in the inter-commutation period, which, of course, is reflected in the electromagnetic torque ripple. 

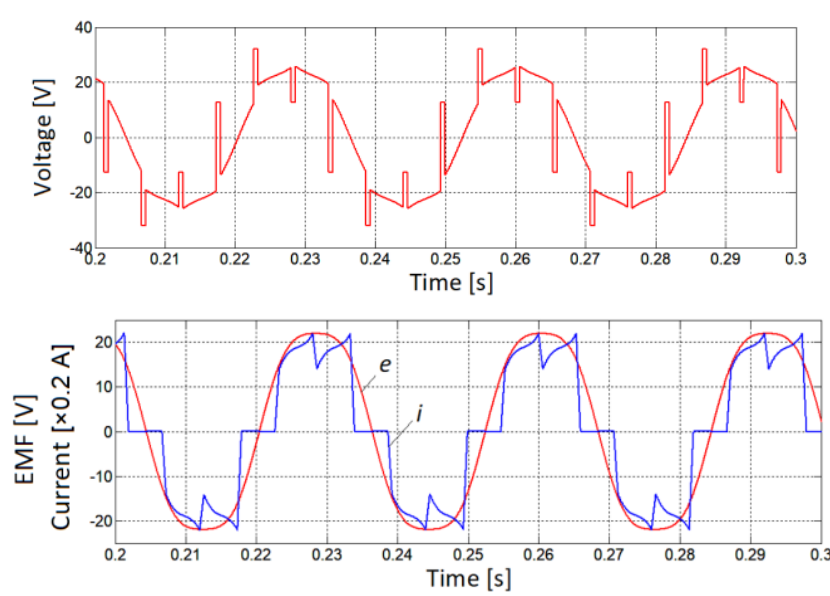

(a)
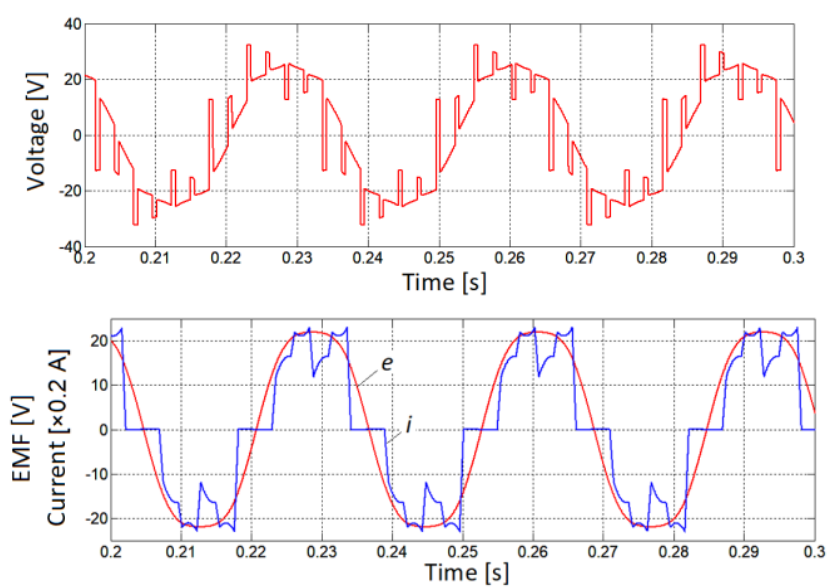

(b)

Figure 16. Shapes of the main variables in one phase of the studied DTP BLDC drive at open-loop operation without (a) and with (b) magnetic coupling between the winding sets: from top to bottom-the voltage, EMF $e$ (red), and current $i$ (blue).

\subsection{T TP BLDC Drive}

Figures 17 and 18 show the same waveforms as Figures 15 and 16, but for the TTP BLDC drive. They were obtained in the simulation by the model shown in Figure 5, but with three modules and parameters of the drive in accordance with Table 2.
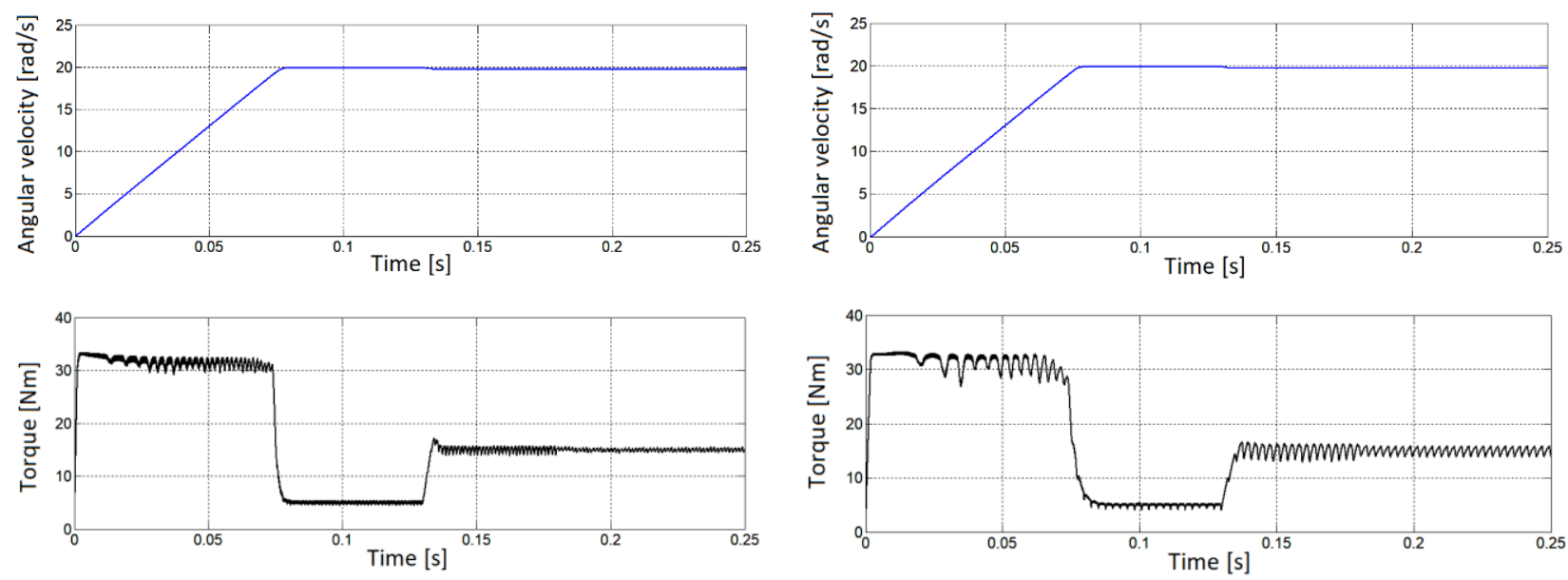

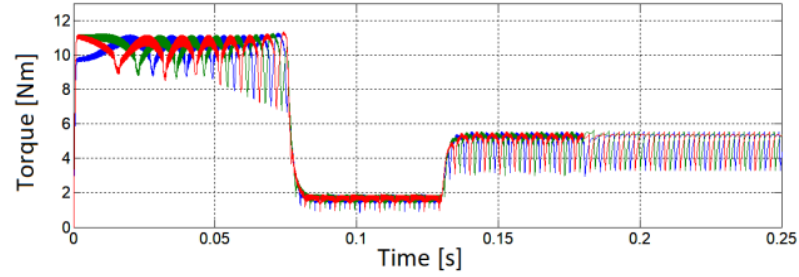

(a)

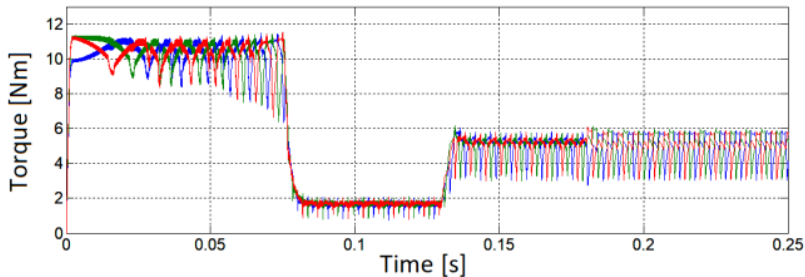

(b)

Figure 17. Waveforms of the output variables of the studied TTP BLDC drive without (a) and with (b) magnetic coupling between the winding sets: from top to bottom-angular velocity, total electromagnetic torque and electromagnetic torques of three modules (by different colors). 

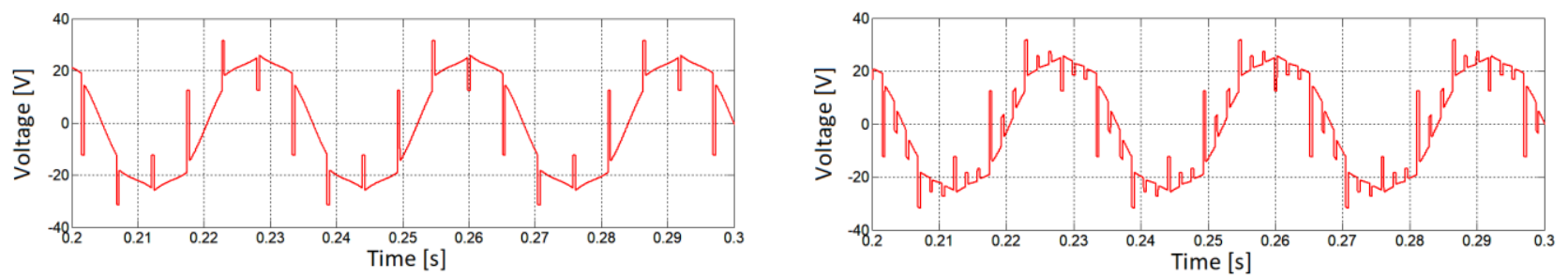

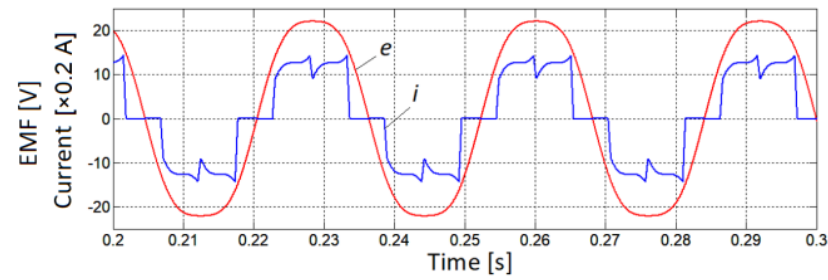

(a)

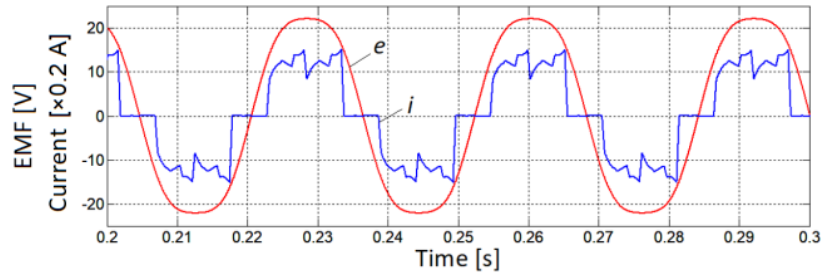

(b)

Figure 18. Shapes of the main variables in one phase of the studied TTP BLDC drive at open-loop operation without (a) and with (b) magnetic coupling between the winding sets: from top to bottom-the voltage, EMF $e$ (red), and current $i$ (blue).

\subsection{QTP BLDC Drive}

Figures 19 and 20 show the analogous to previous modular drives waveforms for the QTP BLDC drive obtained in the simulation.
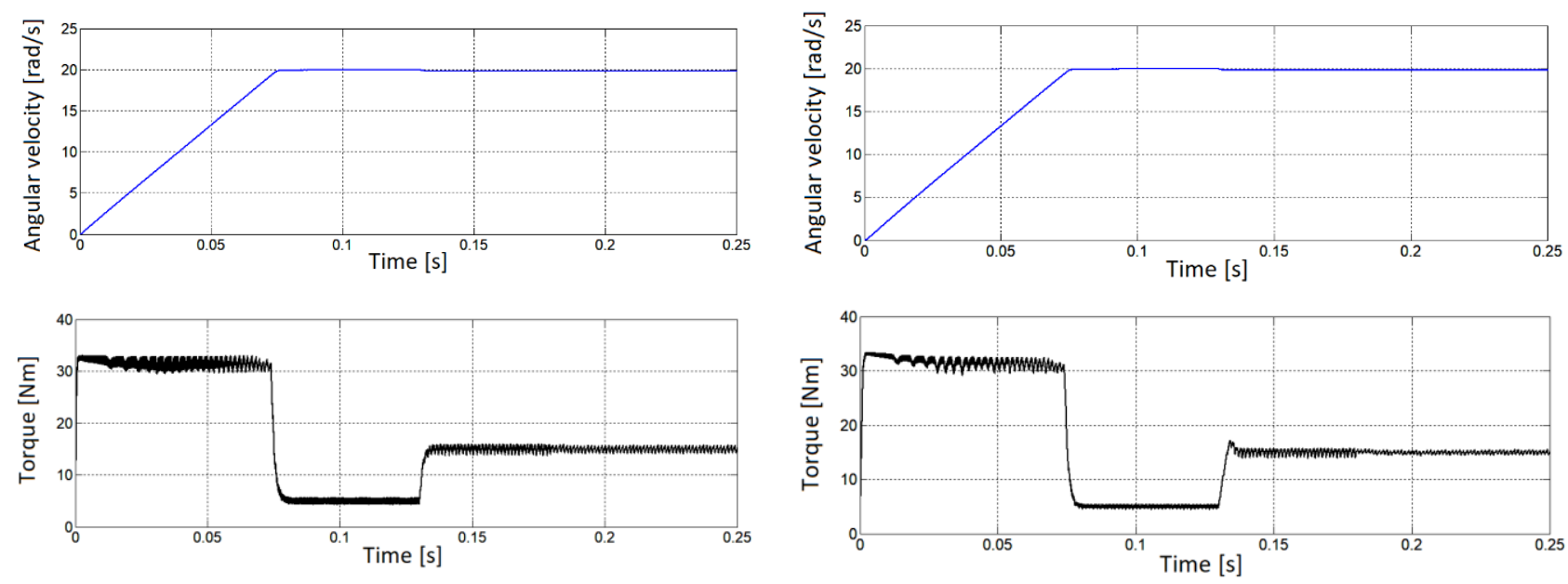

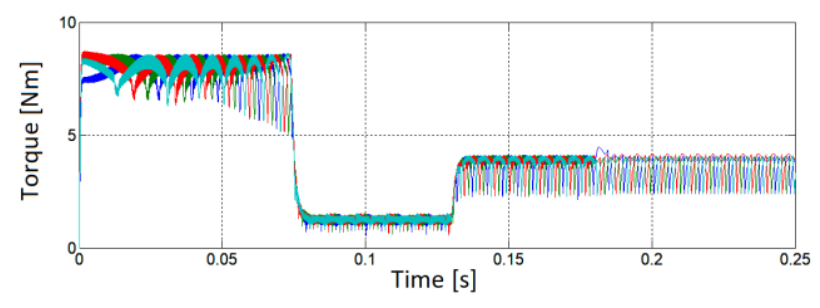

(a)

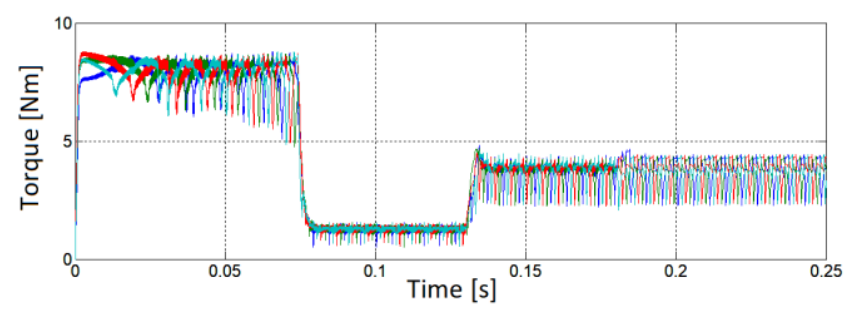

(b)

Figure 19. Waveforms of the output variables of the studied QTP BLDC drive without (a) and with (b) magnetic coupling between the winding sets: from top to bottom-angular velocity, total electromagnetic torque and electromagnetic torques of four modules (by different colors). 

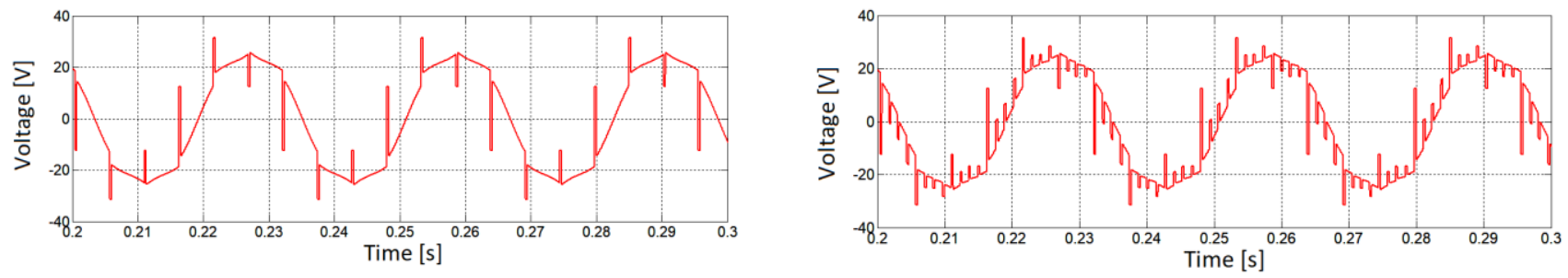

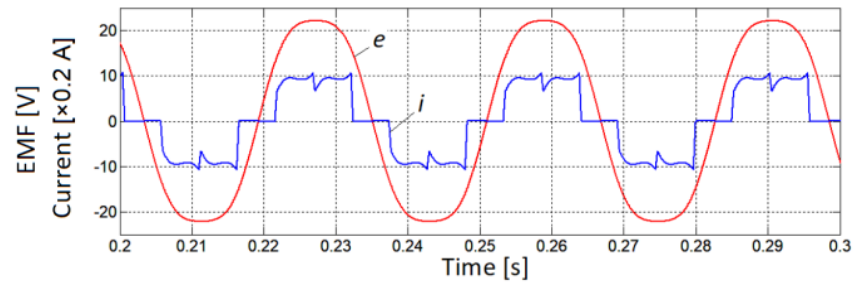

(a)

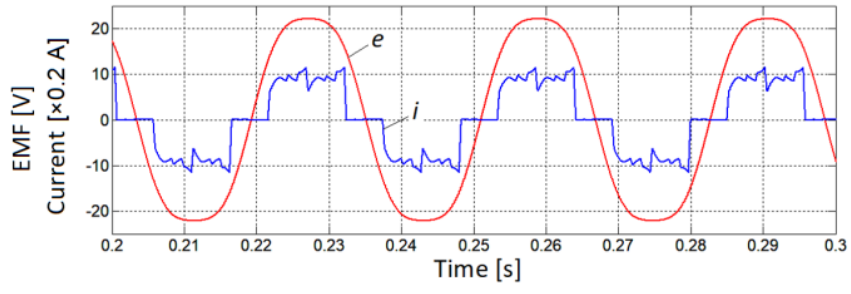

(b)

Figure 20. Shapes of the main variables in one phase of the studied QTP BLDC drive at open-loop operation without (a) and with (b) magnetic coupling between the winding sets: from top to bottom-the voltage, EMF $e$ (red), and current $i$ (blue).

\section{Experimental Verification of the DTP BLDC Drive Model}

To verify the constructed mathematical and computer models of multiple-TP BLDC drives, an experimental BLDC drive based on the DTP PM machine of asymmetrical configuration with an external rotor was created, the photo of which is shown in Figure 21. Parameters of the studied electric machine, determined experimentally and by modeling of its magnetic field by the FE method [38], are used in the computer model of the DTP PM machine shown in Figure 5.

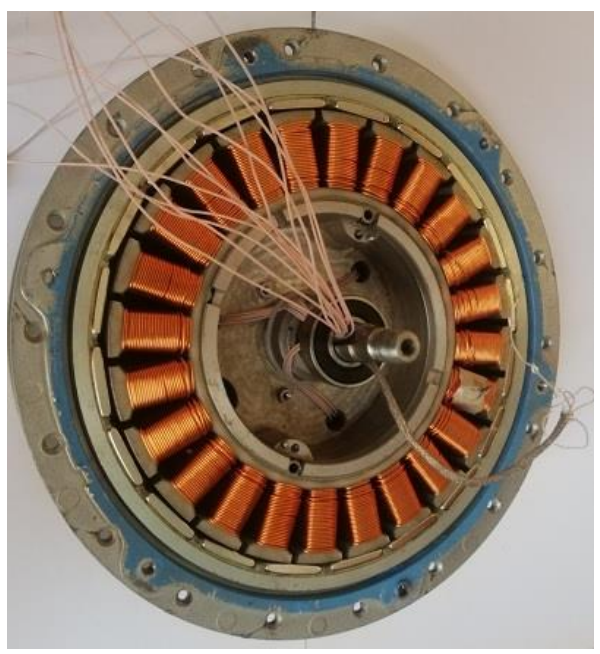

Figure 21. Sample of the studied DTP PM machine.

As a rotor position sensor, a miniature absolute magnetic semiconductor encoder AS5045 with a 12-bit code is used. This is a chip with integrated Hall elements, which is mounted on the end of the fixed stator shaft. A cylindrical magnet is glued to a rotating motor coupling. For six-step electronic switching of the two armature winding sets offset by $30^{\circ}$ el., the microcontroller selects discrete signals synchronized with the EMFs of these sets from the data received via a serial interface from the specified sensor.

Two VSIs are built on MOSFET IRF3205 with IR2104 drivers, and a simple Arduino PRO mini Atmega168 microcontroller controls their switching based on the rotor position.

The completely experimental stand is shown in Figure 22. The power supply of both VSIs was carried out from two blocks of stabilized voltage PS-305D. The studied DTP PM machine is jointed with a DC generator through a toothed belt mounted on the outer rotor 
of the studied machine. The generator is loaded on a resistor that regulated the loading torque of the drive.

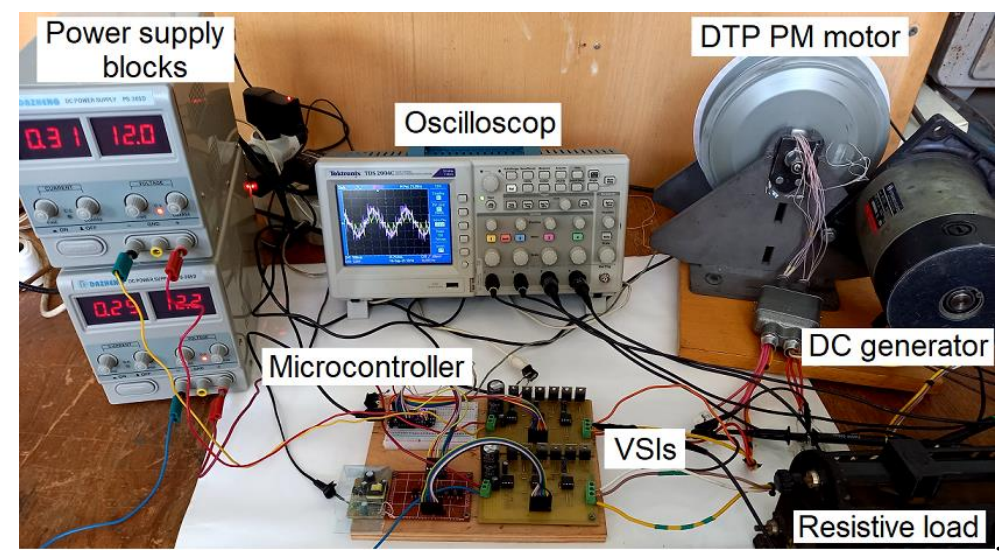

Figure 22. Experimental stand of the DTP BLDC drive.

Figure 23 shows the obtained experimentally and by simulation waveforms of the phase voltage and current in one winding set of the studied open-loop DTP BLDC drive at the same supply voltage, angular speed, and load torque. A comparison of these two results shows their satisfactory coincidence that indicates the sufficient adequacy of the mathematical model of the studied DTP PM machine developed in Section 3. Certain errors between the experimental and theoretical results are explained by the assumptions made in Section 3, which greatly simplified the construction of computer models and provided high speed of simulation. However, the obtained errors are not critical for this study, which aims to obtain the relative results of comparing the level of the electromagnetic moment ripples in multiple TP BLDC drives with different degrees of modularity.

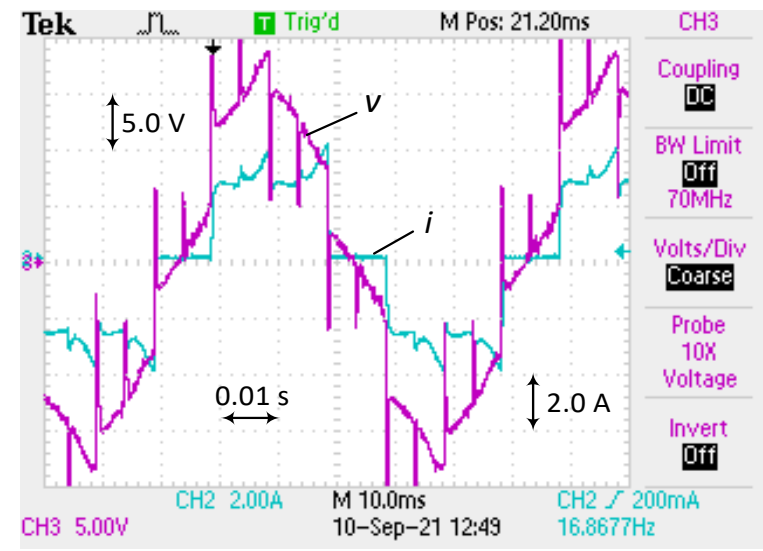

(a)

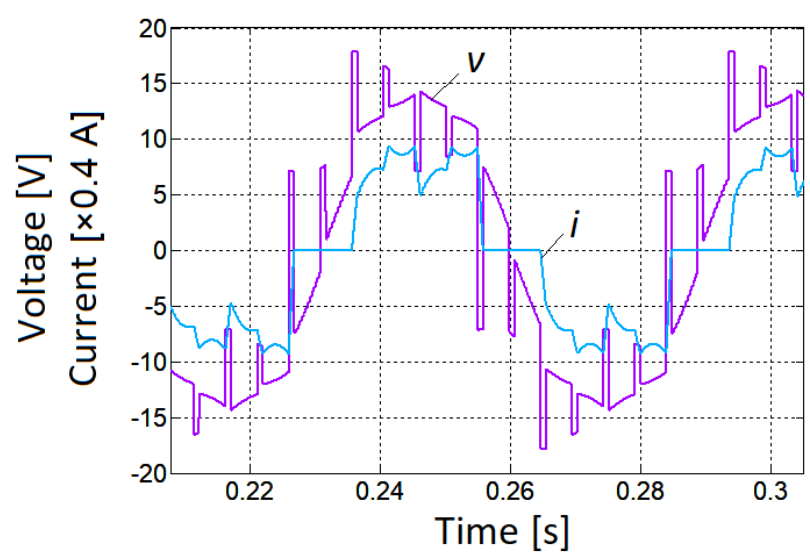

(b)

Figure 23. Waveforms of the phase voltage $v$ (violet) and current $i$ (blue) in one winding set of the studied open-loop DTP BLDC drive: (a) obtained experimentally and (b) obtained in simulation.

\section{Discussion of the Obtained Results}

Analysis of the waveforms for the multiple TP BLDC drives, obtained in the simulation, allows us to draw a number of conclusions.

From the moment of $0.13 \mathrm{~s}$, when there are steady-state modes with rated values of the angular velocity and load torque in all variants of the studied BLDC drives, we can compare the electromagnetic torque ripples at the same nominal parameters-in closed control systems up to $0.18 \mathrm{~s}$, and in open systems after $0.18 \mathrm{~s}$. In the case of magnetically uncoupled armature winding sets (Figures 13,15a, 17a and 19a), the pulsations of electro- 
magnetic torques generated by individual modules after opening the automatic control systems remain at the same level as in closed control systems. At the same time, the total electromagnetic torque of multiple TP BLDC drive in an open system has even slightly less ripple than in a closed one. In the case of magnetically coupled armature winding sets (Figures 15b, 17b and 19b), the pulsations of electromagnetic torques generated by individual modules increase significantly due to the generation of additional current pulsations in magnetically coupled armature winding sets, as shown in Figures 16b, 18b and 20b. The operation of the control system somewhat reduces these ripples, but after opening the automatic control systems, they grow to their natural appearance. However, if you look at the total electromagnetic torque, its pulsations in an open system are much smaller than in a closed one. This indicates a better mutual compensation of natural pulsations of electromagnetic torques of individual multiple TP BLDC drive modules than of those "distorted" by the control system. All this shows that the traditional control system with negative current feedback can stabilize the current only in the inter-switching time intervals, and during the complex process of armature winding switching, simple current control in BLDC drive cannot reduce the electromagnetic torque ripple. Similar results were obtained by us using another common BLDC drive structure, in which an additional DC-DC converter provided the automatic voltage regulation of each module, and the VSI performed only positional low-frequency switching of the armature winding set according to the Hall sensor signals. Therefore, to reduce this ripple in BLDC drives, other methods are required, based on hardware and software improvements, which has already been discussed in the introduction. For multiple TP BLDC drives, such methods still need to be developed.

In order to compare the nature of the electromagnetic torque ripple in the studied multiple TP BLDC drives, Table 3 is given below, in which the torque ripple is defined as a difference between the maximum $T_{e} \max$ and minimum $T_{e}$ min torque values in steady state. The relative magnitude of the electromagnetic torque ripple was determined by the expression

$$
\delta T_{e}=\frac{T_{e \max }-T_{e \min }}{T_{e} \text { ave }}=\frac{\Delta T_{e}}{T_{e} \text { ave }}
$$

where $T_{e}$ ave is the average value of the electromagnetic torque.

Table 3. Torque ripples in the different studied open-loop multiple TP BLDC drives.

\begin{tabular}{|c|c|c|c|c|c|c|c|c|}
\hline \multirow{3}{*}{$\begin{array}{l}\text { Type of } \\
\text { BLDC } \\
\text { Drive }\end{array}$} & \multicolumn{4}{|c|}{ Magnetically Uncoupled Machine Modules } & \multicolumn{4}{|c|}{ Magnetically Coupled Machine Modules } \\
\hline & \multicolumn{2}{|c|}{ One Module } & \multicolumn{2}{|c|}{ Modular System } & \multicolumn{2}{|c|}{ One Module } & \multicolumn{2}{|c|}{ Modular System } \\
\hline & $\Delta T_{e}(\mathrm{Nm})$ & $\delta T_{e}(\%)$ & $\Delta T_{e}(\mathrm{Nm})$ & $\delta T_{e}(\%)$ & $\Delta T_{e}(\mathrm{Nm})$ & $\delta T_{e}(\%)$ & $\Delta T_{e}(\mathrm{Nm})$ & $\delta T_{e}(\%)$ \\
\hline STP & 6.20 & 41.3 & 6.20 & 41.3 & - & - & - & - \\
\hline DTP & 3.25 & 21.7 & 3.10 & 20.7 & 5.10 & 34.0 & 2.05 & 13.7 \\
\hline TTP & 2.25 & 15.0 & 2.1 & 14.0 & 2.85 & 19.0 & 1.35 & 9.0 \\
\hline QTP & 1.35 & 9.0 & 1.15 & 7.7 & 2.05 & 13.7 & 1.10 & 7.3 \\
\hline
\end{tabular}

The results show that an increase in the number of modules in the PM machine always leads to a decrease in pulsations of both one module and the total electromagnetic torque, and both in machines with magnetically uncoupled winding sets and in the presence of magnetic coupling between modules. However, the degree of reduction of the total electromagnetic torque ripples, compared to pulsations of the electromagnetic torque produced by single module in the multiple TP BLDC drives with magnetically coupled winding sets, is much greater than in drives with magnetically isolated winding sets. If for magnetic insulation, this reduction is only $1.0-1.3 \%$, in the case of magnetically coupled winding sets it increases to $20.3 \%$ in DTP, $10.0 \%$ in TTP, and $6.4 \%$ in QTP BLDC drives. This decrease in total electromagnetic moment ripple is due not only to a significant increase in the ripple of the torques generated by each of the magnetically coupled winding sets, but 
also to better mutual compensation of these torques compared with magnetically isolated winding sets. Therefore, the total electromagnetic torque ripples in multiple TP BLDC drives with magnetically coupled winding sets are lower by $7.0 \%$ for DTP, $5.0 \%$ for TTP, and $0.4 \%$ for QTP drives compared to those for magnetically isolated winding sets. This is achieved thanks to the optimal angular displacement of the winding sets in the modular PM machine of asymmetrical configuration; the electromagnetic torques generated by the individual modules are evenly offset within the switching angle for a single-winding machine which equals $60^{\circ} \mathrm{el}$.

In an open-loop system, even with a slight deviation of the supply DC voltages applied to the VSIs, the loads of the machine modules make a big difference. This leads to changes in the shape of currents in the winding sets, as well as to a further increase of the total electromagnetic torque ripple. This explains the additional, often specific, need for automatic control in closed-loop systems in order to equalize currents or electromagnetic torques of the modules in real drive systems, where the supply voltages of these modules are not equal to each other $[39,40]$.

Based on the analysis of the obtained results, the following recommendations can be made on the use of multiple TP BLDC drives for EVs to ensure their fault tolerance and energy efficiency.

1. In order to obtain high specific power and torque of the drive, as well as to reduce the ripple of the total electromagnetic torque, it is necessary to use drives with magnetically coupled winding sets.

2. Since low pulsations of the total electromagnetic torque are achieved only with symmetrical loading of modules, in the TTP BLDC drive at different loads, only one or all three modules can work, i.e., such drive has two levels of power change. The DTP BLDC drive, which is simpler to perform, has the same two levels but with $4.7 \%$ higher pulsations of the total electromagnetic torque at full load of the drive. This gives the advantage of using the DTP BLDC drive for lower power EVs.

3. Reliable and energy-efficient drives for higher power EVs should be built according to the configuration of the QTP BLDC drive. In addition to smaller total electromagnetic torque ripple, such a modular drive can work effectively with one, two (1-2-3 and 7-8-9 or 4-5-6 and 10-11-12 in Figure 2), or four symmetrically loaded armature winding sets, i.e., it has three levels of power change.

\section{Conclusions}

Thus, the conducted studies showed another advantage inherent in multiple threephase BLDC drives-the reduction of ripple of the total electromagnetic torque due to the asymmetrical configuration of the modular PM machine with optimal angular displacement between armature winding sets. As follows from Table 3, compared to traditional STP BLDC drive, there are reductions of the electromagnetic torque ripple in the modular drives with magnetic coupling between the armature winding sets by $27.6 \%$ in the DTP BLDC drive, by $32.3 \%$ in the TTP BLDC drive, and by $34.0 \%$ in the QTP BLDC drive. Further reduction of the total electromagnetic torque ripple in the multiple three-phase BLDC drives can be achieved due to the development of new, special for these drives, automatic current control systems in individual modules. The available number of point sensors of the rotor position in the modular BLDC drives will make it possible to form current estimators for modules with a much lower current ripple level.

In the future, we plan to study the efficiency of multiple TP BLDC drives with different numbers of operating machine modules at different speeds and loads. The efficiency maps obtained as a result of such studies will serve as a basis for the sizing of modular BLDC drives for different kinds of EVs, as well as the substantiation of algorithms for energy management systems, which will control the efficient operation of modules in transport cycles. 
Author Contributions: Conceptualization, I.S. and D.J.; methodology, I.S.; software, D.J.; formal analysis, I.S.; investigation, D.J.; writing-original draft preparation, I.S. and D.J.; experimental verification, I.S.; writing-review and editing, I.S. and D.J.; supervision, I.S. All authors have read and agreed to the published version of the manuscript.

Funding: This research received no external funding.

Conflicts of Interest: The authors declare no conflict of interest.

\section{References}

1. Skouras, T.A.; Gkonis, P.K.; Ilias, C.N.; Trakadas, P.T.; Tsampasis, E.G.; Zahariadis, T.V. Electrical vehicles: Current state of the art, future challenges, and perspectives. Clean Technol. 2020, 2, 1-16. [CrossRef]

2. Stippich, A.; van der Broeck, C.H.; Sewergin, A.; Wienhausen, A.H. Key components of modular propulsion systems for next generation electric vehicles. CPSS Trans. Power Electron. Appl. 2020, 2, 249-258. [CrossRef]

3. Shchur, I.; Turkovskyi, V. Integrated system of modular power supply and multilevel control of brushless DC motor for electric vehicles. Nauk. Visnyk Natsionalnoho Hirnychoho Universytetu 2020, 6, 107-115. [CrossRef]

4. Kuznetsov, B.; Bovdui, I.; Nikitina, T.; Kolomiets, V.; Kobilyanskiy, B. Multi-motor plant related electric drives robust control synthesis. In Proceedings of the 2020 IEEE 4th International Conference on Intelligent Energy and Power Systems (IEPS), Istanbul, Turkey, 7-11 September 2020; pp. 242-245.

5. Shchur, I.; Kasha, L.; Bukavyn, M. Efficiency evaluation of single and modular cascade machines operation in electric vehicle. In Proceedings of the 2020 IEEE 15th International Conference on Advanced Trends in Radioelectronics, Telecommunications and Computer Engineering (TCSET), Lviv-Slavske, Ukraine, 25-29 February 2020; pp. 156-161. [CrossRef]

6. Barrero, F.; Duran, M.J. Recent advances in the design, modeling, and control of multiphase machines, Part I. IEEE Trans. Ind. Electron. 2015, 63, 449-458. [CrossRef]

7. Galassini, A.; Costabeber, A.; Gerada, C.; Buticchi, G.; Barater, D. A modular speed-drooped system for high reliability integrated modular motor drives. IEEE Trans. Ind. Appl. 2016, 52, 3124-3132. [CrossRef]

8. Zhao, W.; Xu, L.; Liu, G. Overview of permanent-magnet fault-tolerant machines: Topology and design. CES Trans. Electr. Mach. Syst. 2018, 2, 51-64. [CrossRef]

9. Zoric, I.; Jones, M.; Levi, E. Arbitrary power sharing among three-phase winding sets of multiphase machines. IEEE Trans. Ind. Electron. 2018, 65, 1128-1139. [CrossRef]

10. Patel, V.I.; Wang, J.; Nugraha, D.T.; Vuletić, R.; Tousen, J. Enhanced availability of drivetrain through novel multiphase permanentmagnet machine drive. IEEE Trans. Ind. Electron. 2016, 63, 469-480. [CrossRef]

11. Ahmad, M.; Wang, Z.; Yan, S.; Wang, C.; Wang, Z.; Zhu, C.; Qin, H. Comparative analysis of two and four current loops for vector controlled dual-three phase permanent magnet synchronous motor. Electronics 2018, 7, 269. [CrossRef]

12. Eldeeb, H.; Abdelrahem, M.; Hackl, C.; Abdel-Khalik, A.S. Enhanced electromechanical modeling of asymmetrical dual threephase IPMSM drives. In Proceedings of the 2018 IEEE 27th International Symposium on Industrial Electronics (ISIE), Cairns, Australia, 13-15 June 2018; pp. 126-132. [CrossRef]

13. Un-Noor, F.; Padmanaban, S.; Mihet-Popa, L.; Mollah, M.; Hossain, E. A comprehensive study of key electric vehicle (EV) components, technologies, challenges, impacts, and future direction of development. Energies 2017, 10, 1217. [CrossRef]

14. Negahdari, A.; Yepes, A.G.; Doval-Gandoy, J.; Toliyat, H.A. Efficiency enhancement of multiphase electric drives at light-load operation considering both converter and stator copper losses. IEEE Trans. Power Electron. 2019, 34, 1518-1525. [CrossRef]

15. Salem, A.; Narimani, M. A Review on multiphase drives for automotive traction applications. IEEE Trans. Transp. Electrif. 2019, 5, 1329-1348. [CrossRef]

16. Basler, B.; Greiner, T.; Heidrich, P. Fault-tolerant strategies for double three-phase pmsm used in electronic power steering systems. In Proceedings of the 2015 IEEE Transportation Electrification Conference and Expo (ITEC), Dearborn, MI, USA, 14-17 June 2015; pp. 1-6. [CrossRef]

17. Cao, W.; Mecrow, B.C.; Atkinson, G.J.; Bennett, J.W.; Atkinson, D.J. Overview of electric motor technologies used for more electric aircraft (mea). IEEE Trans. Ind. Electron. 2012, 59, 3523-3531. [CrossRef]

18. Bogusz, P.; Korkosz, M.; Powrózek, A.; Prokop, J.; Wygonik, P. An analysis of properties of the BLDC motor for unmanned aerial vehicle hybrid drive. In Proceedings of the 2015 International Conference on Electrical Drives and Power Electronics (EDPE), Tatranska Lomnica, Slovakia, 21-23 September 2015; pp. 458-464. [CrossRef]

19. Shchur, I.; Turkovskyi, V. Open-end winding dual three-phase BLDC motor drive system with integrated hybrid batterysupercapacitor energy storage. In Proceedings of the 2021 IEEE 20th Conference on Modern Electrical and Energy Systems (MEES), Kremenchuk, Ukraine, 21-24 September 2021; p. 6.

20. Niapour, S.A.; Garjan, G.H.; Shafiei, M.; Feyzi, M.R.; Danyali, S.; Bahrami Kouhshahi, M. Review of permanent-magnet brushless DC motor basic drives based on analysis and simulation study. Int. Rev. Electr. Eng. (IREE) 2014, 9, 930-957. [CrossRef]

21. Chang, F.; Ilina, O.; Lienkamp, M.; Voss, L. Improving the overall efficiency of automotive inverters using a multilevel converter composed of low voltage Si mosfets. IEEE Trans. Power Electron. 2019, 34, 3586-3602. [CrossRef] 
22. Guo, Q.; Zhang, C.; Li, L.; Wang, M.; Wang, T. Efficiency optimization control of permanent magnet synchronous motor system with SiC MOSFETs for electric vehicles. In Proceedings of the 2017 20th International Conference on Electrical Machines and Systems (ICEMS), Sydney, Australia, 11-14 August 2017; p. 5. [CrossRef]

23. Sumega, M.; Zoššák, Š.; Varecha, P.; Rafajdus, P. Sources of torque ripple and their influence in BLDC motor drives. Transp. Res. Procedia 2019, 40, 519-526. [CrossRef]

24. Vaiyapuri, V.; Jeevananthan, S. Hybrid converter topology for reducing torque ripple of BLDC Motor. IET Power Electron. 2017, 10, 1572-1587. [CrossRef]

25. Naik, M.D.; Agrawal, V.; Naik, M.V.; Yadav, S.; Agarwal, A.; Jaiswal, R. Torque ripple reduction of BLDC motor using modular multilevel converter. In Proceedings of the 2018 International Conference on Computing, Power and Communication Technologies (GUCON), Greater Noida, India, 28-29 September 2018; pp. 820-824. [CrossRef]

26. Doss, M.A.; Premkumar, E.; Kumar, G.R.; Hussain, J. Harmonics and torque ripple reduction of brushless DC motor (BLDCM) using cascaded H-bridge multilevel inverter. In Proceedings of the 2013 International Conference on Power, Energy and Control (ICPEC), Dindigul, India, 6-8 February 2013; pp. 296-299. [CrossRef]

27. Buja, G.; Bertoluzzo, M.; Keshri, R.K. Torque ripple-free operation of PM BLDC drives with petal-wave current supply. IEEE Trans. Ind. Electron. 2015, 62, 4034-4043. [CrossRef]

28. Li, Z.; Kong, Q.; Cheng, S.; Liu, J. Torque ripple suppression of brushless DC motor drives using an alternating two-phase and three-phase conduction mode. IET Power Electron. 2020, 13, 1622-1629. [CrossRef]

29. Xia, C.; Chen, H.; Li, X.; Shi, T. Direct self-control strategy for brushless DC motor with reduced torque ripple. IET Electr. Power Appl. 2018, 12, 398-404. [CrossRef]

30. Tong, C.; Wu, F.; Zheng, P.; Yu, B.; Sui, Y.; Cheng, L. Investigation of magnetically isolated multiphase modular permanent-magnet synchronous machinery series for wheel-driving electric vehicles. IEEE Trans. Magn. 2014, 50, 8203704. [CrossRef]

31. Zhang, H.; Wallmark, O. Evaluation of winding arrangements in electric machinery for modular electric drives. In Proceedings of the 2016 IEEE 8th International Power Electronics and Motion Control Conference (IPEMC-ECCE Asia), Hefei, China, 22-26 May 2016; pp. 2820-2825. [CrossRef]

32. Bogusz, P.; Korkosz, M.; Prokop, J. A study of dual-channel brushless DC motor with permanent magnets. In Proceedings of the 2016 13th Selected Issues of Electrical Engineering and Electronics (WZEE), Rzeszow, Poland, 4-8 May 2016; p. 6.

33. Li, G.J.; Ren, B.; Zhu, Z.Q. Design guidelines for fractional slot multi-phase modular permanent magnet machines. IET Electr. Power Appl. 2017, 11, 1023-1031. [CrossRef]

34. Yokoi, Y.; Higuchi, T.; Miyamoto, Y. General formulation of winding factor for fractional-slot concentrated winding design. IET Electr. Power Appl. 2016, 10, 231-239. [CrossRef]

35. Keller, D.; Karayel, A.; Parspour, N. Comparison of two different winding sets for dual three-phase permanent magnet machines. In Proceedings of the 2019 9th International Electric Drives Production Conference (EDPC), Esslingen, Germany, 3-4 December 2019; p. 6. [CrossRef]

36. Yolacan, E.; Guven, M.K.; Aydin, M.; El-Refaie, A.M. Modeling and experimental verification of an unconventional 9-phase asymmetric winding PM motor dedicated to electric traction applications. IEEE Access 2020, 8, 70182-70192. [CrossRef]

37. Dieterle, O.; Greiner, T. Impact of the magnetic coupling in a quadruple-star permanent magnet synchronous machine with segmented stator windings. In Proceedings of the 2017 IEEE International Electric Machines and Drives Conference (IEMDC), Miami, FL, USA, 21-24 May 2017; p. 8. [CrossRef]

38. Makarchuk, O.; Kharchyshyn, B.; Kasha, L. Analysis of the magneto-mechanical characteristic of double three-phase PMSM. In Proceedings of the 2021 IEEE 3d Ukraine Conference on Electrical and Computer Engineering (UKRCON), Lviv, Ukraine, 26-28 August 2021; pp. 333-338.

39. Yan, H.; Xu, Y.; Zou, J.; Wang, B.; Jiang, S. A maximum current sharing method for dual-redundancy brushless DC Motor control. In Proceedings of the 2014 17th International Conference on Electrical Machines and Systems (ICEMS), Hangzhou, China, 22-25 October 2014; pp. 1057-1061.

40. Bian, C.; Li, X.; Zhao, G. The peak current control of permanent magnet brushless DC machine with asymmetric dual-three phases. CES Trans. Electr. Mach. Syst. 2018, 2, 29-135. 